\title{
Artificial intelligence in disease diagnostics: A critical review and classification on the current state of research guiding future direction
}

\author{
Milad Mirbabaie $^{1}$ (1) $\cdot$ Stefan Stieglitz ${ }^{2}$ (I) $\cdot$ Nicholas R. J. Frick $^{3}$ (1)
}

Received: 20 February 2021 / Accepted: 26 April 2021/ Published online: 10 May 2021

(c) The Author(s) 2021

\begin{abstract}
The diagnosis of diseases is decisive for planning proper treatment and ensuring the well-being of patients. Human error hinders accurate diagnostics, as interpreting medical information is a complex and cognitively challenging task. The application of artificial intelligence (AI) can improve the level of diagnostic accuracy and efficiency. While the current literature has examined various approaches to diagnosing various diseases, an overview of fields in which AI has been applied, including their performance aiming to identify emergent digitalized healthcare services, has not yet been adequately realized in extant research. By conducting a critical review, we portray the AI landscape in diagnostics and provide a snapshot to guide future research. This paper extends academia by proposing a research agenda. Practitioners understand the extent to which AI improves diagnostics and how healthcare benefits from it. However, several issues need to be addressed before successful application of $\mathrm{AI}$ in disease diagnostics can be achieved.
\end{abstract}

Keywords Artificial Intelligence $\cdot$ AI $\cdot$ Diagnostic $\cdot$ Healthcare $\cdot$ Digital Health $\cdot$ Critical Review

\section{Introduction}

The application of artificial intelligence (AI) provides advantages pertaining to the diagnosis of diseases. The healthcare system is a dynamic and changing environment [1] and medical specialists continually face new challenges with changing responsibilities and frequent interruptions [2, $3]$. This variety regularly leads to the diagnosis of disease becoming a side issue for healthcare experts. In addition,

Milad Mirbabaie

milad.mirbabaie@uni-paderborn.de

Stefan Stieglitz

stefan.stieglitz@uni-due.de

Nicholas R. J. Frick

nicholas.frick@uni-due.de

1 Faculty of Business Administration and Economics, Paderborn University, Paderborn, Germany

2 University of Duisburg-Essen, Professional Communication in Electronic Media/Social Media, Duisburg, Germany

3 Nicholas R. J. Frick, University of Duisburg-Essen, Professional Communication in Electronic Media/Social Media, Duisburg, Germany the clinical interpretation of medical information is a cognitively challenging task [4]. This not only applies to experienced professionals but also to actors with different or little expertise such as young assistant doctors [4, 5]. Medical specialists' available time is usually limited $[2,3]$ and diseases might evolve and patient dynamics change over time $[6,7]$ making diagnostics a highly complex process $[8,9]$. However, an accurate diagnostic process is of central relevance to insure timely treatment and, thus, to achieve safe and effective patient care $[10,11]$.

The importance of $\mathrm{AI}$ as a component of the diagnostic process has been steadily increasing since building systems became more practical $[12,13]$. There is ongoing enthusiasm for and hype about AI [14-16], and both researchers and practitioners focus equally on this technology from multiple perspectives [17-19, 35]. There is no uniform definition for the term AI [20], but considered as "the ability of a machine to perform cognitive functions that we associate with human minds, such as perceiving, reasoning, learning, interacting with the environment, problem solving, decision-making, and even demonstrating creativity" [21]. AI is generally associated with human-like behavior [22] and covers a wide range of research areas, such as natural language processing or robotics [23]. However, current practical applications, 
including healthcare and disease diagnostics, are narrowed down to a specific task [24], and are being developed using machine learning $[12,13]$. Algorithms exploit medical data to generate predictions [22] and continuously learn and develop over time by constantly processing new and updated data [25]. Algorithms acquire information through different types of knowledge and input or over multiple years of experience [25]. Therefore, AI empowered systems are able to process more knowledge compared with humans [223], possibly outperforming them for certain medical tasks.

The application of AI within the diagnostic process supporting medical specialists could be of great value for the healthcare sector and the overall patients' well-being. The integration of AI into existing technical infrastructure accelerates the identification of relevant medical data from multiple sources which are tailored to the needs of the patient and the treatment process [26-29]. Simultaneously, AI unchains silo thinking, such as sharing knowledge across departmental boundaries [30], as information from all involved areas is taken into account. Furthermore, AI generates results based on a larger population rather than on subjective, personal experiences [31] and achieves equal results when using identical medical data and does not rely upon situations, emotions, or time of day [32].

Despite the potential shown by AI as a component of medical diagnosis, to date, no thorough analysis of approaches has been conducted, and a comprehensive conceptualization of algorithms that have been previously applied in the diagnostic process for various diseases remains lacking. Recent studies have examined the application of AI in healthcare in general [33-35] or in specific clinical domains [36]. For example, Jiang et el. [33] focused on classical AI algorithms such as support vector machines and neural networks within the entire healthcare sector. Another study by Rauschert et al. [36] dealt with AI in clinical epigenetics whereby the authors investigated individual treatment characteristics of patients based on genetic and epigenetic profiles. In contrast, our research concentrates on the diagnostic process and to what extent AI is being integrated. Specifically, we aim to provide a classification of the current state of $\mathrm{AI}$ in disease diagnostics and guide future research directions. Our study uncovers which algorithms are particularly suitable for which disease diagnosis and where other approaches may be more advisable. By pointing out explicit performance measurements, we explain the overall suitability of existing strategies. We argue that this is of great interest to researchers and practitioners since the relevance of AI within the diagnostic process will continue to increase. There is an urgent demand for academia to provide an overview of the AI-based approaches that are being applied to understand the intricacy of this ever-evolving research area. To address these pressing issues, our study is guided by the following research question:
RQ: How is artificial intelligence currently applied in healthcare to facilitate the diagnostic process, and what are the pertinent future research directions?

We have followed the latest methodological guidelines for literature reviews $[37,38]$ and conducted a critical review (CR) analyzing existing literature on a broad topic to reveal weaknesses, inconsistencies, problems, or discrepancies [39]. We initially reviewed the status quo based on the existing literature on $\mathrm{AI}$ in medical diagnostics, for which we focused on research articles that dealt with practical applications. This has guided us in portraying the current AI landscape in the diagnostic process, including areas that have not yet been adequately covered. By conducting a critical assessment, we are able to provide scholars with knowledge about future research directions and improvements [38].

This paper structures our understanding of AI algorithms that have been researched as components of medical diagnostics. Researchers will find the overview of application fields helpful when considering unexplored areas where the deployment of AI for healthcare services could be beneficial and future research might be necessary. Practitioners will be better able to understand the extent to which AI improves the diagnostic process and how healthcare specialists and patients, as well as the overall treatment processes, benefit from it. Society will comprehend how AI is likely to be used within diagnostics including its current deliberations. We believe this study will be valuable to drive related research and practical implementations as well as lead to a constructive debate on how AI applications can be further integrated into the diagnostic process to enhance overall patient outcomes.

\section{Related work}

The fundamental goal of the diagnosis of disease lies in determining whether a patient is affected by a disease or not [40]. Diagnosis can be seen as a process or classification or as a "pre-existing set of categories agreed upon by the medical profession to designate a specific condition" [41]. The entire diagnostic process, in general, is a sophisticated [8] and "patient-centered, collaborative activity that involves information gathering and clinical reasoning with the goal of determining a patient's health problem" [10]. The Committee on Diagnostic Error in Health Care developed a conceptual model to comprehend the diagnostic process (cf. Figure 1).

Initially, the patient experiences a health problem associated with the individual's symptoms, which causes the person to contact the healthcare system, where sufficient information is collected via reviewing the patient's clinical history 


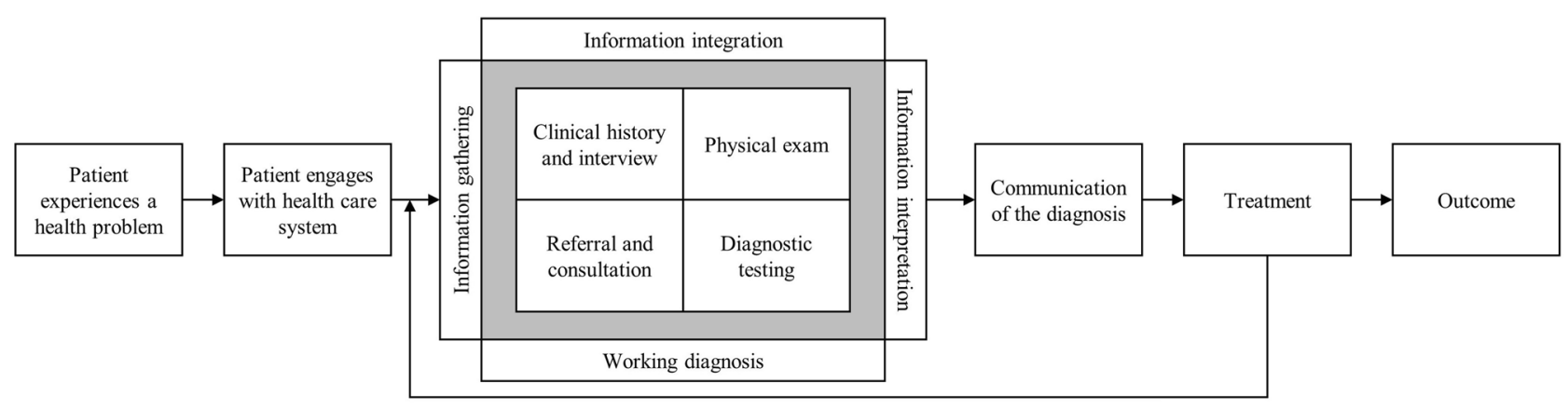

Fig. 1 Conceptualization of the diagnostic process (adapted from [10])

and conducting an interview, performing a physical exam and diagnostic testing, and referral and consultation that involves other medical experts. Information gathering, integration, and interpretation, as well as providing a working diagnosis - for example, a single or differential diagnosistogether represent a continuous process that can be repeated several times. The working diagnosis and an explanation of it are shared with the patient, and appropriate treatment is planned. Finally, this process results in an outcome for patients and the healthcare system, such as learning from errors or a timely diagnosis.

This highly complex process has, on the one hand, great potential for errors and, on the other hand, may vary according to the medical discipline. A diagnosis is usually based on individual experiences of clinicians and may differ depending on the emotional and mental state of the clinician [42]. Medical specialists further have a broad spectrum of duties $[2,3]$, the time they can devote to determining a diagnosis is usually limited. Moreover, since several experts from multiple medical disciplines are needed for a diagnosis [43, 44], the process might be extended even though timeliness is critical when considering further treatment plans [10].

The unique challenges of modern medical practice and the wide variety of diagnostic strategies can create difficulties for the entire healthcare system, and thus, more systems are relying on information technology (IT) [45]. AI is already utilized to assist medical experts and improve the diagnosis of diseases, for example, in early diagnosis of ectopic pregnancies and helping gynecologists with their decisions about initial treatment [46]. This progress is due to improvements of technical capabilities such as processor speed and storage capacity, while costs have dropped [47]. Furthermore, the amount of medical data is continuously growing, and systems are now capable of identifying, extracting, and processing information from different sources more quickly than previously [48, 49]. In addition, the technology and algorithms needed to implement systems are now widely accessible and can be easily applied [50] and are commonly classified in supervised, unsupervised, and deep learning [36, 51].
Supervised learning describes algorithms that learn associations based on existing samples or training data $[52,53]$. Labels of a dataset are known, for example, as images of fractures or ruptures that have been classified by medical specialists. This information is used to train algorithms that generate predictions for unused data [22, 54]. Supervised learning depends on a given user input and is 3 , thus sensitive to data quality [22]. Poorly or incorrectly labeled data lead to faulty predictions, and trained algorithms might even be biased. Supervised learning is one of the most used AI approaches, as it provides robust classifications [36]. Common examples include logistic regression or neural networks. Supervised learning approaches have been found to aid in the diagnosis of dementia [55] and cancer [56].

Unsupervised learning covers self-organizing algorithms that learn associations without existing samples or training data $[57,58]$. It is well suited for identifying correlations within a dataset but are unable to determine their statistical relevance [59]. Moreover, unsupervised learning might also identify irrelevant clusters if these are grounded in the data. This approach does not necessarily depend on user input but demands verification of the plausibility and salience of the identified clusters [22,60]. Common examples include clustering dimensionality reduction algorithms. Unsupervised learning is used, for example, for hepatitis disease diagnostics [4].

Finally, deep learning algorithms learn correlations among data via evolutionary tests that continually adjust predictions according to the given data [61, 62]. Deep learning might be considered an individual AI approach. However, it must be viewed from various angles due to its capability of combining supervised and unsupervised approaches [36]. It is particularly suitable for handling large datasets with multiple dimensions and input sources $[61,63]$, but the outcome is inexplainable due to its sophisticated structure and thus represents a black box for users, eventually posing a high risk for patients' wellbeing $[64,65]$. Common examples include recurrent neural networks and convolutional neural networks. Examples of deep learning in diagnostics are the classification of dermatological diseases [66] and atrial fibrillation detection [67]. 
The development of supervised, unsupervised, and deep learning algorithms presupposes that the available data can be split into training and test sets $[33,36]$. As part of training, the algorithm is optimized by tweaking different parameters and attributes of the data. Within testing, the performance of the algorithm is validated. Both sets usually use a subset of the same dataset. Their separation does not follow any specific rules, but the training set is normally larger than the test set. An increasingly popular alternative to purposefully separating the data is the use of cross-validation, where the data is randomly split into multiple training and test sets to approximate the external validity of the algorithm [68]. Finally, the algorithm and the generated model are validated using unrelated, unseen data, for example, genuine medical data.

Various performance measurements are applied to evaluate the efficiency of a trained model. The most common measurements found in scientific publications are accuracy, sensitivity, and specificity $[69,70]$. Accuracy estimates the correct classification out of all classifications on a range from $0-1$ (the equivalent of $0-100 \%$ ). Sensitivity explains how many patients with a disease have been correctly identified with this disease (true positive rate), on a range from $0-1(0-100 \%)$. Specificity, in contrast to sensitivity, determines how many patients without a disease have been correctly identified without this disease (true negative rate), on a range from 0-1 (0-100\%) [36]. Thus, higher values for accuracy, sensitivity, and specificity indicate a well-trained model that provides the most accurate results.

\section{Research approach}

The objective of this research lies in identifying in which areas of the diagnostic process AI has already been applied and how these approaches are to be evaluated. We performed a CR to identify relevant literature and analyze it according to the AI algorithms, their medical applications, dataset characteristics, and performance measurements. Since we were interested in providing a holistic picture, we decided to start our literature search within the information systems (IS) discipline. We argue that IS, as interdisciplinary community addressing dynamic and evolving sociotechnical challenges, suit as a valid starting point for guiding medical specialists. Within the individual steps of the research procedure, we expanded our search to other scientific domains and outlets. For example, we identified publications from healthcare (e.g., Annals of Emergency Medicine) and biomedical engineering (e.g., Computers in Biology and Medicine).

As CRs are frequently performed in an unsystematic manner [39], but benefit from an informative explanation of how the literature was retrieved [37], we adopted a systematic approach in our research procedure. This insured that we would avoid having a subjective aggregation of existing literature [39] but instead make a significant contribution by searching for the most relevant literature using keywords in scientific databases [71, 72]. We used a descriptive review focus since an interpretable pattern from the existing literature would thereby be generated [73], leading to a depiction of the current state of our research domain [74]. The research procedure, as illustrated in Fig. 2, considers articles up until December 2020.

The literature search was conducted with the help of litbaskets.io, a novel IT artifact specifically designed to assist researchers in retrieving relevant literature from credible scientific sources [75]. Unlike in other areas, for example in medicine or psychology, there is no uniform database including the broad spectrum of outlets for conducting comprehensive literature searches in the IS discipline. Litbaskets assists scholar in the concise and precise selection of relevant publications. Technically, a search string is created which is used by Scopus's advanced search, making it possible to seek across indexed scientific sources [75]. Thus, litbaskets does not collect articles itself, but uses the ISSN numbers of selected outlets to grasp articles according to the search term.

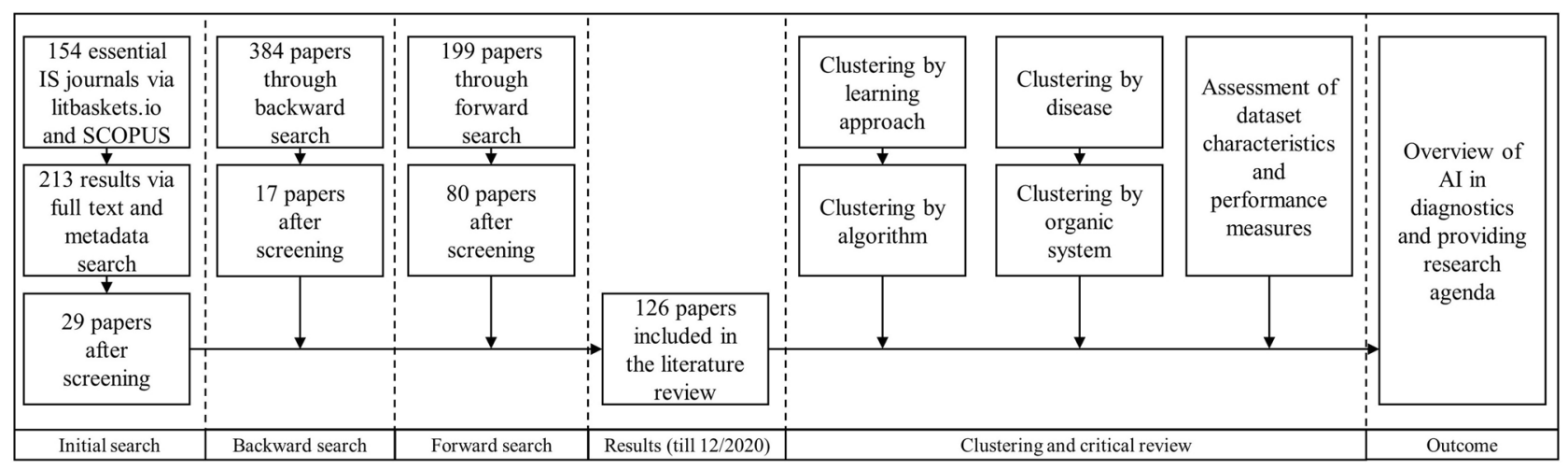

Fig. 2 Research procedure 
We deliberately chose 154 essential IS journals because we wanted to focus on substantial and high-quality articles. ${ }^{1}$ The literature search considered all peer-reviewed articles; less relevant sources, such as editorials, were excluded. We carried out a full text and metadata search; we deliberately did not limit it to metadata only, as it cannot be guaranteed that the search term is always contained in the metadata, thus possibly resulting in overlooking relevant publications. We used the following query for our full text search:

\section{(AI or "artificial intelligence") and (diagnostic or diagnostics)}

We purposely chose a rather broad term pursuing a central concept of CRs: analyzing a research topic using a wider scope compared to other procedures [39], aiming to reveal "weaknesses, contradictions, controversies, or inconsistencies" [38]. We used the terms AI and artificial intelligence as well as the plural spelling of diagnostic covering the focus of our research. We did not use, for example, certain names of machine learning algorithms to avoid needlessly limiting our search. For concentrating on retrieving literature of $\mathrm{AI}$ in disease diagnostics while bypassing narrowing down our initial search, we further did not include related terms to diagnostic, such as diagnosis or diagnose. This ensures a thorough analysis of existing approaches as a broad term is crucial for providing a comprehensive overview yielding in an agenda guiding future directions.

After retrieving the literature, we carefully read the title, abstract, and keywords of each publication to determine its relevance to our research question. We focused on papers that specifically considered and applied AI in the context of diagnostics. Our guiding questions were: Which AI methods were applied to improve the diagnostic process? What algorithm is used for which diseases, and how can medical specialists be assisted in the diagnosis of diseases? How have algorithms been developed for disease diagnostics? How accurate are the results of the individual applications? Publications that compared algorithms under theoretical conditions or those that did not disclose the applied algorithm were not considered in our research.

Since a basic search is not able to provide a comprehensive review, and we were highly interested in retrieving relevant literature outside the IS discipline, we further conducted a backward search to identify additional literature. We collected all references listed in the bibliographies of all the papers from the initial search, in which we only included references to other scientific publications, such as web pages,

\footnotetext{
${ }^{1}$ For a full list of the included journals, please see https://www. litbaskets.io/.
}

panel discussions, or business reports which did not fit our research goals. The relevance of the papers was determined via the same approach we used within the initial search: we read the title, abstract, and keywords, which was followed by categorization according to theoretical foundations. The final step included a forward search to further identify relevant publications, whereby we acknowledged all papers that were retrieved in the initial and backward searches. We were interested in articles that had been cited by other researchers after their initial publication. Once again, we read the title, abstract, and keywords and performed the categorization process as outlined above. We deliberately did not decide adding keywords for filtering or excluding, for example, theory driven research articles to prevent overlooking relevant literature. Even though this manual process was very time consuming, it simultaneously ensured gathering the largest possible number of relevant publications.

Following the recommendation of Bem [76] for a conceptual structuring of the research topic, the categories of the examined disease and applied learning type served as a conceptual pre-structure whereby the literature was roughly categorized. Afterwards, we examined and compared the retrieved literature to identify correlations and similarities. Prior research was then grouped based on its theoretical foundations and finally reviewed concerning quantitative criteria. We initially clustered the publications according to the learning types, using supervised and deep learning, as these approaches provide more clinical results and are thus more likely to be found in healthcare [33]. A cross-check further revealed only one paper that dealt with unsupervised learning. Following Jiang et al. [33], we then used the most common machine learning algorithms applied to develop AI applications $[12,13,22]$ as classifications within supervised and deep learning. This resulted in 12 clusters: neural network, support vector machine, nearest neighbor, random forest, decision tree, logistic regression, naive Bayes, discriminant analysis, convolutional neural network, deep neural network, recurrent neural network, and others. We further clustered the retrieved articles according to their examined disease. Since this approach was rather granular, we assigned the disease to the affected organic system (i.e., cardiovascular, dermatological, gastrointestinal, infectious, metabolic, neurological/psychiatric, pediatric, pulmonary, and urogenital). The resulting classification according to the algorithm combined with the organic system helped us to interpret the results in a more holistic way. Finally, we analyzed the dataset characteristics and performance measurements of the algorithms. The datasets were described by their origin, sample size, number of features (e.g., patient characteristics, such as age or smoker), training, and testing sample. The performance was assessed using accuracy, sensitivity, and specificity. The quality criteria aided us in determining the value of algorithms applied for disease diagnostics as well as 
Table 1 Example publications and exemplary assignment to their categories

\begin{tabular}{llll}
\hline Article & Journal & Organic system & Algorithm \\
\hline$[46]$ & International Journal of Medical Informatics & Urogenital & $\begin{array}{c}\text { Naive Bayes, Recurrent Neural Network, Sup- } \\
\text { port Vector Machine } \\
\text { Convolutional Network }\end{array}$ \\
{$[67]$} & Knowledge-Based Systems & Cardiovascular & Discriminant Analysis, Neural Network, Others \\
\hline [77] & Expert Systems with Applications & Pulmonary & .
\end{tabular}

critically examining whether developments and applications seemed reasonable. Table 1 exemplifies how we performed the categorization by providing example articles and their classification. Please note that one paper might have dealt with multiple algorithms. Table 2 and 3 explain the organic systems and algorithms used for clustering.

\section{Results and analysis}

The execution of the CR resulted in 126 relevant articles, of which 29 were retrieved via the initial search, 17 via the backward search, and, finally, 80 via the forward search. We analyzed the articles according to their distribution by year, publication outlet, distribution by category, and, finally, dataset characteristics and performance measurements. We thereby obtained an overview of the AI-based approaches examined in the literature, including their suitability for the diagnostic process, and critically evaluated these results.

There is no prototype or implementation of a developed algorithm or model that is actually used in healthcare for the purpose of diagnosing diseases or assisting within the diagnostic process. There have been limited studies that presented user interfaces as spin-off product that theoretically provides a basis for its deployment in disease diagnostics. For example, Ogah et al. [78] developed a knowledge-based system including a user interface for diagnosing hepatitis $B$ via a neural network. However, the study focused on the development of the algorithm and underlying database rather than proving a suitable graphical interface for users. Furthermore, most studies have employed textual medical data to implement suitable algorithms for disease diagnostics. Mishra et al. [66] curated a database with 4,700 images of nine common dermatological diseases, such as acne, erythema, or wheal, and used deep learning based for correct classification. Another example is captured transvaginal ultrasounds of pregnant women to detect ectopic pregnancies [46]. Nevertheless, these studies are rather the exception; most approaches have developed a specific algorithm to diagnose a particular disease. A limited fraction of research combines algorithms to achieve better results. For example, decision trees and case-based reasoning were integrated into an intelligent model for liver disease diagnosis, indicating considerable accuracy compared with single method concepts [79]. Likewise, a small number of studies implemented and compared multiple algorithms and considered which one best fit the diagnosis of a disease. Studies performed predictive modeling via multiple algorithms, that is, logistic regression, random forest, decision tree and support vector machine, for the early detection of Parkinson's disease [80]. Lu et al. [56] compared decision tree, logistic regression, nearest neighbor, neural network, and support vector machine to assist in cervical cancer diagnosis. Although there are nascent approaches to compare algorithms, there is no scientific publication that has yet investigated whether one approach is suitable for the diagnosis of several diseases.

\subsection{Distribution of articles by year}

No articles were published before 1990, but articles related to AI in diagnostics have increased substantially over time (cf. Figure 3). Since 2013, the number of publications has risen considerably, which is in accord with technological improvements of AI. The increasing number of studies is a product of the enhanced and ever-growing technical capabilities and the quantity of medical data $[47,50]$. The constant growth of publications reflects not only the increased demand for AI within the disease diagnostics but also represents the salience and legitimacy of this research area.

\subsection{Distribution of articles by outlet}

From a total of 126 articles, $105(83.3 \%)$ were in journals, and only $19(16.7 \%)$ were conference publications. Most articles $(52,41.3 \%)$ came from 12 outlets and were published in practice-oriented journals. This is understandable since we explicitly searched for articles that examined AI within the diagnostic process. The highest number of journal articles were published in Expert Systems with Applications (15, 11.9\%). Furthermore, a large portion of publications were from outside the IS discipline; this was acceptable and suspectable as our focus was clearly on the applications in healthcare. Thus, most practical applications of AI in disease diagnostics were to be found in medical outlets. Table 4 outlines the distribution of articles by outlets with more than one publication.

\subsection{Distribution of articles by category}

Among the organic systems, cardiovascular disorders clearly stood out as the most heavily researched area, with 34 articles 
Fig. 3 Total number of articles per year

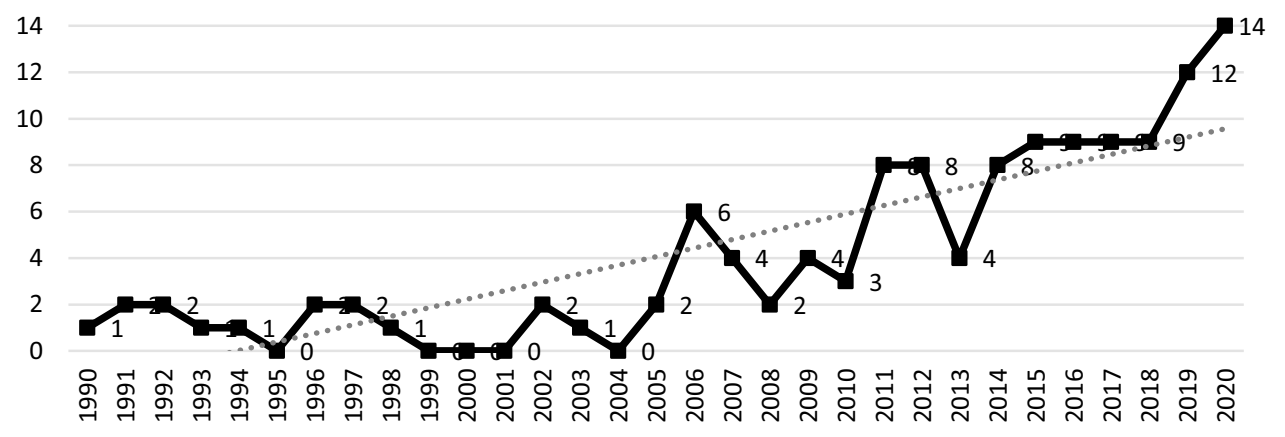

(27.0\%). Neurological/psychiatric $(20,15.9 \%)$, cancer $(18$, $14.3 \%)$, gastrointestinal disease $(15,11.9 \%)$, and infectious disorders $(13,10.3 \%)$ have all been studied with similar intensity. The least published articles were found for pulmonary and urogenital disease, with four articles each $(3.1 \%)$. The small number of papers might indicate a lack of perspective for those research fields. In the case of the algorithms, neural networks were by far the most researched area, with 71 articles (42.5\%) examining this algorithm in the context of the diagnosis of diseases. The support vector machine was the second most researched area, with 35 articles (21.0\%). Deep learning approaches, such as, deep neural network $(2,1.2 \%)$ and recurrent neural network $(2,1.2 \%)$, as well as a mixture of other applied algorithms, which do not fall under the scope of our classification, were the least considered algorithms. Table 5 depicts the number of artciles in each category.

For validating if a research domain has received much attention and whether certain areas are highly correlated, we compared the organic systems and algorithms the papers have dealt with using a research assignment matrix (cf. Table 2). We matched the corresponding organic systems with each algorithm. The illustration aided us in examining and allocating the results of the large number of relevant publications. The matrix provides an overview of the status quo-areas with less research do not indicate that further studies are inevitably required there. However, the matrix highlights that transferring previously gained knowledge of the application of AI within diagnostics to other research areas seems possible and advisable. It appears that most of the algorithms were already being used in the diagnosis of neurological/psychiatric diseases (10), followed by cardiovascular and gastrointestinal disorders (7), and urogenital diseases (7). Dermatological, infectious, metabolic, and pulmonary diseases (3) were the least examined. In terms of the algorithms, neural networks (8) and support vector machines (8) were the most researched. Both methods have been applied to the diagnosis of diseases for nearly every

Table 2 Explanation of organic systems used for clustering

\begin{tabular}{ll}
\hline Organic system & Description \\
\hline Cancer & $\begin{array}{c}\text { Cancer begins with an abnormal cell that develops over time into a mass } \\
\text { of cells and can then metastasize, thus spreading to other locations } \\
\text { in the body [130]. Depending on the type of cancer, the treatment is } \\
\text { frequently complicated, and an illness might lead to death. There are } \\
\text { more than 200 different types of cancer, all of which are treated differ- } \\
\text { ently [130]. Well-known examples are breast [131], cervical [132], or } \\
\text { liver [133] cancer } \\
\text { Cardiovascular disorders include diseases of the heart or blood vessels } \\
\text { as well as vascular diseases of the brain [134]. It is known as the } \\
\text { leading cause of death and disability in the world, with more than 17 } \\
\text { million deaths per year [135]. Specific examples are acute myocardial } \\
\text { infarction [116], coronary artery disease [136], or atrial fibrillation }\end{array}$ \\
$\begin{array}{ll}\text { [67] } \\
\text { Dermatological examinations deal with normal and abnormal skin and } \\
\text { include its associated structures, e.g., hair, nails, and oral and genital } \\
\text { mucous membranes [137]. Skin diseases are very common: almost } \\
\text { one-third of all humans are affected by them in the course of their } \\
\text { lives [137]. Examples are erythemato-squamous disease [138] or } \\
\text { psoriasis [96] }\end{array}$ \\
\hline
\end{tabular}


Table 2 (continued)

\begin{tabular}{|c|c|}
\hline Organic system & Description \\
\hline Gastrointestinal & $\begin{array}{l}\text { Gastrointestinal disorders involve disease of the digestive system, the } \\
\text { most important connection between absorbed nutrients and the human } \\
\text { body [139], and often occur as a result of abnormal behavior of the } \\
\text { gastrointestinal tract [140]. These might be chronic disorders, such as } \\
\text { chronic kidney disease [106], but also include lesser-known illnesses } \\
\text { such as cirrhosis [141] or celiac disease [121] }\end{array}$ \\
\hline Infectious & $\begin{array}{l}\text { Infectious diseases, commonly known as transmissible diseases, } \\
\text { describe clinically evident illnesses where an organism is capable of } \\
\text { entering, surviving, and multiplying in a human host [142]. Typical } \\
\text { transmission paths include physical contact, contaminated food, or } \\
\text { body fluids [142]. The different forms of hepatitis are among the most } \\
\text { commonly referred to infectious diseases [4, 102]. Tuberculosis is also } \\
\text { classified as an infectious disease [143] }\end{array}$ \\
\hline Metabolic & $\begin{array}{l}\text { Metabolic disorders might occur when the normal metabolic processes } \\
\text { of the human body are altered by abnormal chemical reactions [144]. } \\
\text { Disorders of the metabolism are accompanied by dynamic changes } \\
\text { but are usually well treatable [144]. Different types of diabetes [145] } \\
\text { are associated with it, but this category also includes diseases such as } \\
\text { osteoporosis [127] or thyroid disease [146] }\end{array}$ \\
\hline Neurological/psychiatric & $\begin{array}{l}\text { The neurological/psychiatric (neuropsychiatry) category comprises } \\
\text { organically conditioned cognitive and mental disorders and is thus } \\
\text { overlaps with the medical research fields of psychiatry, neurology, and } \\
\text { psychology [147]. The classic neuropsychiatric diseases with symp- } \\
\text { toms in both the neurological and psychiatric fields are Parkinson's } \\
\text { [148], dementia [55], and autism [149] }\end{array}$ \\
\hline Pediatric & $\begin{array}{l}\text { Pediatric diseases are disorders that explicitly occur during child- } \\
\text { hood. Research has shown that the treatment of childhood diseases } \\
\text { differs significantly from those contracted by adults [150], justifying } \\
\text { physicians caring for children holistically. Common examples of such } \\
\text { diseases are neonatal sepsis [109] or abdominal pain [151] }\end{array}$ \\
\hline Pulmonary & $\begin{array}{l}\text { Pulmonary diseases are related to problems with the lungs [152]. } \\
\text { Patients often experience breathing problems, shortness of breath, or } \\
\text { coughing [153]. In addition to chronic obstructive pulmonary disease } \\
\text { [153], asthma [112] is also a common lung disease }\end{array}$ \\
\hline Urogenital & $\begin{array}{l}\text { Urogenital disorders are problems that directly affect the urinary } \\
\text { and genital tracts [150]; they are further differentiated according to } \\
\text { whether a person is only temporarily affected or for life. Urogenital } \\
\text { disorders comprise, for example, urinary tract infections [154], but } \\
\text { ectopic pregnancy [46] is to be included as well }\end{array}$ \\
\hline
\end{tabular}

organic system. Deep learning approaches, that is, deep (1), recurrent (2), and convolutional neural networks (4) have not been much applied in diagnostics. They are currently limited to the diagnosis of only a few diseases.

\subsection{Dataset characteristics and performance measures}

The examined literature varied considerably in its depth of detail and presentation of the data used as well as the results achieved. Table 6 outlines example dataset characteristics and performance measures.

$\mathrm{ACC}=$ Accuracy, $\mathrm{SEN}=$ Sensitivity, $\mathrm{SPE}=$ Specificity, $\mathrm{SP}=$ Sample, $\mathrm{FR}=$ Features, $\mathrm{TR}=$ Training, $\mathrm{TE}=$ Testing, $?=$ no information, $\mathrm{cv}=$ cross validation.
We distinguished the origin of datasets as self-retrieved information (37), using an existing database (51), medical data grounded on other studies (7), and not providing any details (31). The results showed that most of the studies did not reveal detailed information on the data origin or how the data were collected, including circumstances or contexts. However, an in-depth presentation and explanation of the origin of medical data used to develop algorithms for disease diagnostics is a vital component for interpreting outcomes and verifying whether findings are adaptable and generalizable. A positive example was presented by [46] who used clinical data based on a long-term study from the Department of Obstetrics and Gynecology of the University Hospital "Virgen de la Arrixaca" in the Murcia region of Spain from November 2010 to September 2015. A total of 
Table 3 Explanation of algorithms

\begin{tabular}{ll}
\hline Type & Algorithm \\
\hline Supervised learning & Decision Tr
\end{tabular}

Supervised learning Decision Tree

Logistic Regression

Naive Bayes

Nearest Neighbor

Neural Network

Random Forest

Support Vector Machine

Deep learning Convolutional Neural Network

Deep Neural Network

Recurrent Neural Network

Description

Decision trees classify instances through sorting them based on their individual value [155]. A decision tree always consists of a root node and several inner nodes and at least two leaves. Each node represents a logical rule and each leaf an answer to the problem

Logistic regression algorithms aim at finding relationships between variables, which are refined in multiple iterations to predict an output value (or multiple values) based on given input features [156]. The output might be a finite number of states

Naive Bayes is based on the Bayes theorem and represents a simple graphical model (directed acyclic graph) for the determination of relationships among various features [155]. The goal is to present the most compact probability distribution of involved variables by using known conditional independence

Nearest neighbor is used for assessing the probability of classification (class membership) or regression (property value) [157]. The outcome is based on the nearest similar values (e.g., nearest neighbors)

Neural networks are networks based on connected artificial neurons comparable to the human brain. Information flows through different layers within the network, whereby the final result can be manipulated by weighting the individual neurons [155]

Random forest algorithms are a type of decision trees building up a multitude of trees with ranging depths [158]

Support vector machines classify subjects into two groups using a hyperplane (support vector), i.e. a two-dimensional space [33, 36]

Convolutional neural networks are based on neural networks but are useful for processing data with multiple spaces, for example 2D- or 3D-images [61], by using an activation function for each neuron

Deep neural networks are highly complex neural networks with substantially higher amounts of layers [159]

Recurrent neural network is - like convolutional neural network, useful for but data with multiple space [61] but uses output of one neuron used as input for another or itself feedback loops, i.e., the output of a neuron suits as input for another neuron or even itself

Other Others

There are other, less-known approaches, such as dimensionality reduction or regularization algorithms. However, in the context of this study, these play an insignificant role, which is why no detailed description is provided at this point

406 cases of tubal ectopic pregnancies of women from 16 to 46 years of age visiting the emergency room or the firsttrimester-pathology unit were collected. The authors elaborated on personal and medical variables, outlined which data were gathered, such as 2D transvaginal ultrasound, and who examined the patients. Most studies developed an algorithm based on medical data from an existing database (e.g., Machine Learning Repository of the University of California at Irvine ${ }^{2}$ ). This does not necessarily entail any negative

\footnotetext{
${ }^{2}$ http://archive.ics.uci.edu/ml/index.php
}

consequences. However, one might argue that researchers are more familiar with self-retrieved data leading to better results in terms of algorithms' efficiencies. Existing data might be used with the objective of testing a developed algorithm without really aiming to diagnose a disease, instead just fulfilling a purpose.

The quantitative details of the datasets have also shown considerable discrepancies among the studies. Other than a few articles (9), the majority outlined the exact sample size of the dataset; however, the number varies considerably, ranging from 9 to 212,554 . Studies have rarely used a 
Table 4 Distribution of articles by outlets with more than one publication

\begin{tabular}{lc}
\hline Journal & Number of publications \\
\hline Expert Systems with Applications & $15(11.9 \%)$ \\
Journal of Medical Systems & $7(5.6 \%)$ \\
International Journal of Medical Informatics & $7(5.6 \%)$ \\
Computer Methods and Programs in Biomedicine & $5(4.0 \%)$ \\
Annals of Emergency Medicine & $3(2.4 \%)$ \\
IEEE Access & $3(2.4 \%)$ \\
Annals of Internal Medicine & $2(1.6 \%)$ \\
Computers in Biology and Medicine & $2(1.6 \%)$ \\
Information Sciences & $2(1.6 \%)$ \\
International Conference on Neural Networks & $2(1.6 \%)$ \\
International Journal of Computer Applications & $2(1.6 \%)$ \\
International Journal of Healthcare Information Systems and Informatics & $2(1.6 \%)$ \\
\hline
\end{tabular}

large dataset $(N>1,000)$, and we found only a subset of nine publications which considered large samples. For example, [67] analyzed atrial fibrillation using a convolutional neural network based on 150,060 samples. In contrast, [89] examined 53 patients to diagnose osteoporosis. Small sample sizes hinder the possibility for a generalization to a larger population; thus, results must be interpreted with caution. There is no "one size fits all" answer to the requirement for a minimum sample size. However, larger samples are favorable for achieving better results [90] especially since small datasets frequently lack in detecting certain patterns [91-93]. Furthermore, small sample size produce bias even if there are above 1000 records used [94].

The identified training and testing samples first showed that the data were usually split according to certain patterns (e.g., 60/40, 70/30, 80/20). However, it is remarkable that only a small number of studies (26) used cross-validation to randomly split the data to approximate the external validity of the algorithm and thus generate better outcomes [68]. Furthermore, the algorithms are typically trained and tested via a subset of the dataset and afterwards validated using the same entire dataset again. This is a common approach, nevertheless, it seems arbitrary as the results are analyzed in isolation without the inclusion of separate and previously unknown medical data.

Similar to the characteristics of the datasets, the reporting of the performance measures was rather patchy. Sixty-six out of the 126 studies reported detailed information on the three measures. The remaining publications were missing at least one value, whereby accuracy was usually used to assess the efficiency of the algorithm. However, reporting accuracy as a single performance measurement might be misleading [95]. The results of the studies were mostly quite promising; the overall accuracy ranged from 61.42 to $100.00(M=86.85$; $S D=24.82)$, sensitivity from 59.00 to $100.00(M=62.82$; $S D=43.84)$, and specificity from 60.53 to $100.00(M=58.32$;
$S D=45.42$ ). Shrivastava et al. [96] contributed a solid example for thorough reporting of necessary performance measures while achieving high results for disease classification in dermatology. However, other studies failed to grant insights into their performance, hindering the interpretation of findings on a more general level.

The evaluation of algorithms in disease diagnostics without knowing detailed information about the used dataset and achieved efficiencies prevents the generalization of results and transferring them into a different context. The need for comprehensive information is crucial in understanding studies justification and contribution to theory and practice. There is frequently too much information missing for undertaking an adequate evaluation.

\section{Discussion and future directions}

We critically reviewed identified publications according to both strengths and weaknesses. Following the recommendations for CRs [38], we set out to determine directions for future research. We categorized our findings under a suitable heading that deals with identical or similar issues. Table 7 and 8 summarizes exemplary future research questions according to the four identified areas.

\subsection{Advancements and explicability}

Recent studies have been primarily concerned with the development of a specific algorithm for the detection of a particular disease [87, 124]. Moreover, some algorithms have been more researched than others. Future research should examine possible advancements by combining the various existing algorithms to achieve better results compared with the isolated observation of a single algorithm $[97,98]$. We strongly recommend more research in the field 
of deep learning for disease diagnostics so large amounts of medical data can be processed faster [61, 62] and satisfying results can more likely be reached $[67,81]$. However, an essential technical restriction of the more complex but performant deep learning approaches lies in the fact that the results of AI remain a black box to humans [125]. The outcomes are not always comprehensible, which makes it, on the one hand, nearly impossible to learn from the AI's decisions and, on the other hand, challenging to build trust in the system itself. Future research should therefore focus on improving the understandability and explainability of AI derived conclusions [99]. A transparent prediction-making process leads to a trustworthy relationship between the AI and medical experts [100]. Overall, we offer the following research proposition $(\mathrm{RP})$ :

RP1: We propose more research on how AI can be implemented to achieve better diagnostic results. Novel development strategies need to ensure understandability and explainability of the AI's result and create a transparent and trustworthy environment in which medical experts are assisted.

\subsection{Corroboration and portability}

There has been a recent development of AI algorithms which aim to assist in the diagnostic process, and which generally consider a single dataset based on textual input. There have been numerous studies indicating satisfying results [126, 127]. However, there is a certain risk that results are not applicable to other domains and only deliver proper results for a specific application. Future research needs to corroborate these findings in a diverse patient population [116]. This can be achieved by using heterogeneous and larger datasets (i.e., with $\mathrm{N}>1,000$ samples) $[55,89,96,101-109]$ with a range of formats such as X-ray images or ultrasounds [56, 110] which are currently almost neglected. Furthermore, larger datasets should commonly be splitted using crossvalidation to approximate external validity thus generate better outcomes [68]. Simultaneously, findings need to be transferred to other types of diseases, for example, different types of cancer [67, 87, 111-113, 118], but also to other clinical application [100, 114, 115, 117]. In addition, one must ask why scientific evidence is not yet widely integrated into disease diagnostics, for instance, in hospitals or other clinical environments. The question remains whether AI approaches persist in real-world scenarios $[118,128]$. Thus, portability is a crucial factor in the future of $\mathrm{AI}$ in disease diagnostics $[116,119]$. Thus, we offer the following proposition:

RP2: We propose more research on how AI in diagnostics can be adapted in other clinical environments and confirmed using larger datasets with enhanced validity. Additionally, we suggest the examination of
AI for diagnosing disease in a real-world scenario, confirming its practical suitability.

\subsection{Integration and collaboration}

The diagnosis of different diseases is a strongly subjective process and a cognitively challenging task that depends on the clinician's individual experience and differs based on the emotions and mental state [4, 42]. With the application of AI to the diagnostic process, medical experts are assisted by AI, possibly leading to superior results. However, current research on $\mathrm{AI}$ in disease diagnostics has exclusively dealt with technical implementations rather than being concerned with how AI might be integrated into existing technical infrastructure. Recent AI development may yield sufficient results for diagnosing diseases; however, it is still unknown in which way data will be presented to medical practitioners. Diagnostics still presupposes collaboration between humans and AI [129]. This requires intensified research on integration practices, especially on the development of user-friendly interfaces for multiple devices [66, 79, 83, 118, 121]. Researchers and healthcare practitioners should aim to develop AI in collaboration to reach a better outcome for patients [100]. Scientific endeavors could go even further by developing a system that could assist in the entire diagnostic process instead of just focusing on diagnosing a particular disease [122]. Furthermore, we argued earlier that collaboration between humans and AI can yield superior results. However, due to a lack of practical examples, future research needs to take a closer look at collaborative aspects when humans partner with $\mathrm{AI}$ in the diagnostic process. It may be that virtual human-AI teams outperform humans working in isolation [123]. This brings us to our final proposition:

\begin{abstract}
RP3: We propose more research on how AI can be integrated into existing technical infrastructure for assisting within the diagnostic process using suitable interfaces running on multiple devices. Moreover, scholars need to examine whether virtual teams consisting of humans and AI outperform medical teams or single expert efforts when diagnosing diseases.
\end{abstract}

\section{Conclusion and limitations}

In this article, we have illustrated the application of AI within diagnostics in current academic research. We presented our CR, which classified the retrieved literature according to organic systems, algorithms, dataset characteristics, and performance measurements. These results are useful for practitioners and healthcare researchers.

The main theoretical contribution of this research is the proposal of a research agenda including exemplary research 
questions. We thereby seek to guide researchers' efforts to encourage future research in the field of AI as part of medical diagnostics. Furthermore, illustrating the intensity of studies, highly correlated areas, and an overview of unexplored research is helpful for future deployment of AI for diagnosing diseases. On a practical level, practitioners understand the extent to which AI improves the diagnostic process and how the overall healthcare system benefits from it. Medical professionals understand how AI can be applied to diagnosing diseases, which could result in having suitable suggestions for further developing AI-based approaches. In addition, healthcare experts comprehend which challenges still need to be tackled before disease is diagnosed in collaboration with AI. In terms of implications for society, readers realize that AI is likely to be used in healthcare to diagnose diseases or at least assist during the process. Nevertheless, the application of AI as a component of the diagnostic process provides opportunities for innovative digital health and is simultaneously able to ensure enhanced patient outcomes.

This research is not free of limitations. First, it should be noted that not all existing AI-based algorithms were used in our classification. We classified a few approaches with "other which may indicate that these algorithms have been applied either rarely or probably not at all for diagnostic purposes. In addition, it could indicate that these algorithms are simply not suitable for application within the process of medical diagnosis. Furthermore, we looked at publications that have dealt exclusively with the technical application of algorithms. Therefore, we have limited our research and may have missed the retrieval of relevant literature dealing with $\mathrm{AI}$ in the diagnostic process from which we could have acquired additional findings. Moreover, in respect to future research directions, researchers might consider looking at the entire course of the diagnostic process and whether and how AI can be used in ways other than the diagnosis of disease Table 9 and 10.

\section{Appendix}

Table 5 Number of articles in categories (one paper might have dealt with multiple algorithms)

\begin{tabular}{llll}
\hline Organic system & Number of papers & Algorithm & Number pf papers \\
\hline Cardiovascular & $34(27.0 \%)$ & Neural Network & $71(42.5 \%)$ \\
Neurological/psychiatric & $20(15.9 \%)$ & Support Vector Machine & $35(21.0 \%)$ \\
Cancer & $18(14.3 \%)$ & Nearest Neighbor & $11(6.6 \%)$ \\
Gastrointestinal & $15(11.9 \%)$ & Random Forest & $11(6.6 \%)$ \\
Infectious & $13(10.3 \%)$ & Decision Tree & $10(6.0 \%)$ \\
Metabolic & $8(6.4 \%)$ & Logistic Regression & $9(5.4 \%)$ \\
Dermatological & $6(4.8 \%)$ & Naive Bayes & $7(4.2 \%)$ \\
Pediatric & $4(3.1 \%)$ & Discriminant Analysis & $1(0.6 \%)$ \\
Pulmonary & $4(3.1 \%)$ & Convolutional Neural Network & $6(3.6 \%)$ \\
Urogenital & $4(3.1 \%)$ & Deep Neural Network & $2(1.2 \%)$ \\
& & Recurrent Neural Network & $2(1.2 \%)$ \\
Total & & Others & $2(1.2 \%)$ \\
\hline
\end{tabular}


Table 6 Research assignment matrix

\begin{tabular}{|c|c|c|c|c|c|c|c|c|c|c|c|c|c|}
\hline \multirow{10}{*}{ 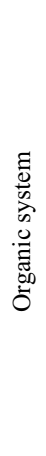 } & Cancer (6/27) & (2) & & (4) & & (2) & (12) & (3) & (5) & & & & \\
\hline & Cardiovascular (7/36) & & & & (2) & (1) & (23) & (1) & (4) & (2) & & & (3) \\
\hline & Dermatological (3/6) & & & & & & & (1) & (2) & & (3) & & \\
\hline & Gastrointestinal (7/19) & (3) & & & (1) & (3) & (7) & & (2) & (2) & & & (2) \\
\hline & Infectious (4/14) & & & & & (1) & (8) & & (4) & & & & (1) \\
\hline & Metabolic (3/9) & & & & & (1) & (6) & & (2) & & & & \\
\hline & Neurological/psychiatric (10/37) & (3) & & (4) & (2) & (1) & (9) & (4) & (10) & (2) & & (1) & (1) \\
\hline & Paediatric (5/7) & (1) & & (1) & (1) & & (3) & (1) & & & & & \\
\hline & Pulmonary (4/6) & & (1) & & & & (2) & & & (1) & & & (2) \\
\hline & Urogenital (7/9) & (1) & & & (1) & (2) & & (1) & (2) & & & (1) & (1) \\
\hline & & 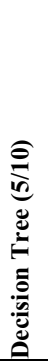 & 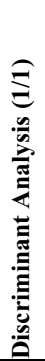 & 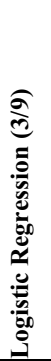 & 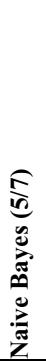 & 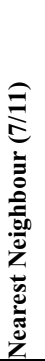 & 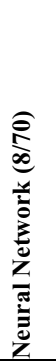 & 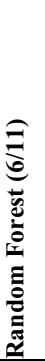 & 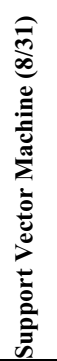 & 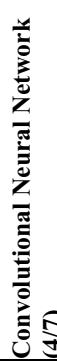 & 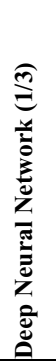 & 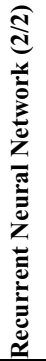 & 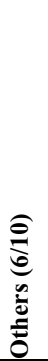 \\
\hline & & & & & & & & ithm & & & & & \\
\hline
\end{tabular}

Table 7 Example dataset characteristics and performance measures

\begin{tabular}{|c|c|c|c|c|c|c|c|c|c|}
\hline Article & Algorithm(s) & ACC & SEN & SPE & Origin & SP & FR & TR & $\mathrm{TE}$ \\
\hline [81] & $\begin{array}{l}\text { Convolutional } \\
\text { Neural } \\
\text { Network }\end{array}$ & 98.00 & 95.83 & 96.87 & $\begin{array}{l}\text { Existing } \\
\text { database }\end{array}$ & 500 & ? & 350 & 100 \\
\hline [82] & $\begin{array}{c}\text { Random } \\
\text { Forest }\end{array}$ & 97.60 & 96.65 & 98.54 & $\begin{array}{l}\text { Existing } \\
\text { database }\end{array}$ & 858 & 32 & $\mathrm{cv}$ & $\mathrm{cv}$ \\
\hline [83] & Others & 91.80 & 89.48 & 95.65 & $\begin{array}{l}\text { Based on } \\
\text { other } \\
\text { study }\end{array}$ & 610 & 42 & 195 & 415 \\
\hline [84] & $\begin{array}{l}\text { Neural Net- } \\
\text { work }\end{array}$ & 96.00 & 91.20 & 94.80 & $\begin{array}{l}\text { Self- } \\
\text { retrieved }\end{array}$ & 995 & 20 & $?$ & $?$ \\
\hline [85] & $\begin{array}{l}\text { Neural Net- } \\
\text { work }\end{array}$ & 93.70 & $?$ & $?$ & $\begin{array}{l}\text { Existing } \\
\text { database }\end{array}$ & 155 & 19 & $\mathrm{cv}$ & $\mathrm{cv}$ \\
\hline
\end{tabular}


Table 8 Future research questions

\begin{tabular}{|c|c|c|}
\hline Area & Example research questions & References \\
\hline Advancements and Explicability & $\begin{array}{l}\text { - How can existing AI developments applied in } \\
\text { disease diagnostics be combined to achieve } \\
\text { better results compared with single algorithm } \\
\text { approaches? } \\
\text { - For which disease is deep learning favorable } \\
\text { for achieving better diagnostic results? } \\
\text { - To what extent can deep learning algorithms } \\
\text { be developed to provide explainable and } \\
\text { understandable results for medical experts } \\
\text { within the diagnostic process? } \\
\text { - How can AI transparently outline diagnostic } \\
\text { results for strengthening the confidence of } \\
\text { healthcare practitioners in the system? }\end{array}$ & {$[67,81,97-100]$} \\
\hline Corroboration and Portability & $\begin{array}{l}\text { - How can existing developments of AI in dis- } \\
\text { ease diagnosis be transferred to other diseases } \\
\text { and/or conditions? } \\
\text { - What results do AI approaches achieve in } \\
\text { disease diagnostics when analyzing deviat- } \\
\text { ing data formats, such as X-ray images or } \\
\text { ultrasounds? } \\
\text { - What are the requirements for using AI in a } \\
\text { real-world scenario of disease diagnostics? } \\
\text { - Which real-world scenario is suitable for the } \\
\text { practical examination of AI within disease } \\
\text { diagnostics? }\end{array}$ & {$[55,56,67,87,89,96,100-119]$} \\
\hline Integration and Collaboration & $\begin{array}{l}\text { - How can AI be integrated into existing } \\
\text { technical environments to assist within the } \\
\text { diagnostic process? } \\
\text { - What are the requirements for designing a } \\
\text { user interface of an AI-based system to assist } \\
\text { with diagnosing diseases? } \\
\text { - What are the prerequisites for a successful } \\
\text { collaboration between medical practitioners } \\
\text { and AI in disease diagnostics? } \\
\text { - To what extent do human-AI teams achieve } \\
\text { superior results compared with human medi- } \\
\text { cal teams in the diagnostic process? }\end{array}$ & {$[4,66,79,83,100,118,120-123]$} \\
\hline
\end{tabular}

Table 9 Complete list of all articles used in the critical review

\begin{tabular}{|c|c|c|c|}
\hline Paper & Organic system & Algorithm(s) & Outlet \\
\hline [126] & Cancer & $\begin{array}{l}\text { Logistic Regression, Neural } \\
\text { Network }\end{array}$ & $\begin{array}{c}\text { International IEEE Confer- } \\
\text { ence Intelligent Systems }\end{array}$ \\
\hline [82] & Cancer & Random Forest & IEEE Access \\
\hline [160] & Infectious & Neural Network & $\begin{array}{l}\text { Iranian Conference on } \\
\text { Electrical Engineering }\end{array}$ \\
\hline [161] & Cancer & $\begin{array}{l}\text { Decision Tree, Nearest Neighbor, } \\
\text { Random Forest, Support Vector } \\
\text { Machine }\end{array}$ & $\begin{array}{l}\text { Expert Systems with } \\
\text { Applications }\end{array}$ \\
\hline [102] & Infectious & Neural Network & Soft Computing \\
\hline [162] & Cardiovascular & Naive Bayes & $\begin{array}{l}\text { International Journal of } \\
\text { Computer Engineering in } \\
\text { Research Trends }\end{array}$ \\
\hline [111] & Cardiovascular & $\begin{array}{l}\text { Naive Bayes, Nearest Neighbor, } \\
\text { Support Vector Machine, Others }\end{array}$ & $\begin{array}{l}\text { International Conference } \\
\text { on Data Mining Work- } \\
\text { shops }\end{array}$ \\
\hline
\end{tabular}


Table 9 (continued)

\begin{tabular}{|c|c|c|c|}
\hline Paper & Organic system & Algorithm(s) & Outlet \\
\hline [110] & Infectious & Neural Network & $\begin{array}{l}\text { 14th International Multi- } \\
\text { topic Conference }\end{array}$ \\
\hline [163] & Cardiovascular & Neural Network & $\begin{array}{l}\text { Computer Methods and } \\
\text { Programs in Biomedicine }\end{array}$ \\
\hline [83] & Cardiovascular & Others & $\begin{array}{l}\text { Expert Systems with } \\
\text { Applications }\end{array}$ \\
\hline [164] & Cardiovascular & Support Vector Machine & $\begin{array}{l}\text { Expert Systems with } \\
\text { Applications }\end{array}$ \\
\hline [84] & Cardiovascular & Neural Network & The Lancet Journal \\
\hline [165] & Cardiovascular & Neural Network & Neural Computation \\
\hline [166] & Cardiovascular & Neural Network & $\begin{array}{l}\text { Annals of Internal Medi- } \\
\text { cine }\end{array}$ \\
\hline [167] & Cardiovascular & Neural Network & $\begin{array}{l}\text { Annals of Emergency } \\
\text { Medicine }\end{array}$ \\
\hline [168] & Cardiovascular & Neural Network & $\begin{array}{l}\text { Neural Computing and } \\
\text { Applications }\end{array}$ \\
\hline [116] & Cardiovascular & Neural Network & $\begin{array}{l}\text { Annals of Internal Medi- } \\
\text { cine }\end{array}$ \\
\hline [169] & Cardiovascular & Neural Network & $\begin{array}{l}\text { Annals of Emergency } \\
\text { Medicine }\end{array}$ \\
\hline [170] & Cardiovascular & Support Vector Machine & $\begin{array}{l}\text { Journal of Medical Sys- } \\
\text { tems }\end{array}$ \\
\hline [119] & Urogenital & $\begin{array}{l}\text { Decision Tree, Nearest Neighbor, } \\
\text { Random Forest }\end{array}$ & $\begin{array}{l}\text { BMC Medical Informatics } \\
\text { and Decision Making }\end{array}$ \\
\hline [85] & Infectious & Neural Network & Dicle Medical Journal \\
\hline [141] & Gastrointestinal & Neural Network & $\begin{array}{l}\text { Expert Systems with } \\
\text { Applications }\end{array}$ \\
\hline [77] & Pulmonary & $\begin{array}{l}\text { Discriminant Analysis, Neural } \\
\text { Network, Others }\end{array}$ & $\begin{array}{l}\text { Expert Systems with } \\
\text { Applications }\end{array}$ \\
\hline [145] & Metabolic & Neural Network & $\begin{array}{l}\text { Expert Systems with } \\
\text { Applications }\end{array}$ \\
\hline [42] & Cancer & $\begin{array}{l}\text { Logistic Regression, Neural } \\
\text { Network }\end{array}$ & $\begin{array}{l}\text { Expert Systems with } \\
\text { Applications }\end{array}$ \\
\hline [112] & Pulmonary & Neural Network & $\begin{array}{l}\text { Mediterranean Conference } \\
\text { on Medical Biological } \\
\text { Engineering }\end{array}$ \\
\hline [171] & Cardiovascular & Neural Network & $\begin{array}{l}\text { International Conference } \\
\text { of the ZEEE Engineering } \\
\text { in Medicine and Biology } \\
\text { Society }\end{array}$ \\
\hline [172] & Pulmonary & Convolutional Neural Network & $\begin{array}{l}\text { Proceedings of the } 2020 \\
\text { Conference on Artifi- } \\
\text { cial Intelligence and } \\
\text { Healthcare }\end{array}$ \\
\hline [128] & $\begin{array}{l}\text { Neurological/psychi- } \\
\text { atric }\end{array}$ & Naive Bayes, Neural Network & $\begin{array}{l}\text { International Conference } \\
\text { on Engineering Applica- } \\
\text { tions of Neural Networks }\end{array}$ \\
\hline [115] & Pulmonary & Others & $\begin{array}{l}\text { Innovative Systems Design } \\
\text { and Engineering }\end{array}$ \\
\hline [46] & Urogenital & $\begin{array}{l}\text { Naive Bayes, Recurrent Neu- } \\
\text { ral Network, Support Vector } \\
\text { Machine }\end{array}$ & $\begin{array}{l}\text { International Journal of } \\
\text { Medical Informatics }\end{array}$ \\
\hline [118] & $\begin{array}{l}\text { Neurological/psychi- } \\
\text { atric }\end{array}$ & Support Vector Machine & Connection Science \\
\hline [127] & Metabolic & Neural Network & $\begin{array}{l}\text { Healthcare Technology } \\
\text { Letters }\end{array}$ \\
\hline
\end{tabular}


Table 9 (continued)

\begin{tabular}{|c|c|c|c|}
\hline Paper & Organic system & Algorithm(s) & Outlet \\
\hline [173] & Cancer & $\begin{array}{l}\text { Logistic Regression, Support Vec- } \\
\text { tor Machine }\end{array}$ & Expert Systems \\
\hline [136] & Cardiovascular & Support Vector Machine & $\begin{array}{l}\text { Computer Methods and } \\
\text { Programs in Biomedicine }\end{array}$ \\
\hline [174] & Cardiovascular & Convolutional Neural Network & $\begin{array}{l}\text { Expert Systems with } \\
\text { Applications }\end{array}$ \\
\hline [86] & Cardiovascular & Neural Network & $\begin{array}{l}\text { International Journal of } \\
\text { Cardiology }\end{array}$ \\
\hline [149] & $\begin{array}{l}\text { Neurological/psychi- } \\
\text { atric }\end{array}$ & $\begin{array}{l}\text { Nearest Neighbor, Random Forest, } \\
\text { Support Vector Machine }\end{array}$ & $\begin{array}{l}\text { Current Psychiatry } \\
\text { Research and Reviews }\end{array}$ \\
\hline [146] & Metabolic & Neural Network & $\begin{array}{l}\text { International Journal on } \\
\text { Computational Sciences } \\
\text { \& Applications }\end{array}$ \\
\hline [98] & $\begin{array}{l}\text { Neurological/psychi- } \\
\text { atric }\end{array}$ & $\begin{array}{l}\text { Neural Network, Support Vector } \\
\text { Machine }\end{array}$ & $\begin{array}{l}\text { Global Journal of } \\
\text { Computer Science and } \\
\text { Technology }\end{array}$ \\
\hline$[175]$ & Urogenital & Others & $\begin{array}{l}\text { International Journal of } \\
\text { Medical Informatics }\end{array}$ \\
\hline [131] & Cancer & Neural Network & $\begin{array}{l}\text { Industrial and Systems } \\
\text { Engineering Research } \\
\text { Conference }\end{array}$ \\
\hline [103] & $\begin{array}{l}\text { Neurological/psychi- } \\
\text { atric }\end{array}$ & $\begin{array}{l}\text { Logistic Regression, Neural Net- } \\
\text { work, Support Vector Machine }\end{array}$ & $\begin{array}{l}\text { Computer Methods and } \\
\text { Programs in Biomedicine }\end{array}$ \\
\hline [176] & Cardiovascular & Neural Network & $\begin{array}{l}\text { Annals of Emergency } \\
\text { Medicine }\end{array}$ \\
\hline [177] & $\begin{array}{l}\text { Neurological/psychi- } \\
\text { atric }\end{array}$ & Neural Network & $\begin{array}{l}\text { Journal of Medical Sys- } \\
\text { tems }\end{array}$ \\
\hline [178] & Infectious & Support Vector Machine & $\begin{array}{l}\text { Journal of Computer Sci- } \\
\text { ence and Information }\end{array}$ \\
\hline [89] & Metabolic & Neural Network & $\begin{array}{l}\text { Journal of Computational } \\
\text { and Theoretical Nanosci- } \\
\text { ence }\end{array}$ \\
\hline [179] & Gastrointestinal & Neural Network & $\begin{array}{l}\text { Expert Systems with } \\
\text { Applications }\end{array}$ \\
\hline [101] & Metabolic & Neural Network & $\begin{array}{l}\text { International Journal on } \\
\text { Artificial Intelligence } \\
\text { Tools }\end{array}$ \\
\hline$[67]$ & Cardiovascular & Convolutional Neural Network & Knowledge-Based Systems \\
\hline [180] & $\begin{array}{l}\text { Neurological/psychi- } \\
\text { atric }\end{array}$ & Logistic Regression & $\begin{array}{l}\text { BMC Medical Informatics } \\
\text { and Decision Making }\end{array}$ \\
\hline$[181]$ & Cardiovascular & Neural Network & $\begin{array}{l}\text { European Medical and } \\
\text { Biological Engineering } \\
\text { Conference }\end{array}$ \\
\hline [129] & $\begin{array}{l}\text { Neurological/psychi- } \\
\text { atric }\end{array}$ & Neural Network & $\begin{array}{l}\text { Computers in Biology and } \\
\text { Medicine }\end{array}$ \\
\hline [120] & Cardiovascular & Neural Network & $\begin{array}{l}\text { Computers in Biology and } \\
\text { Medicine }\end{array}$ \\
\hline [104] & Cardiovascular & Neural Network & $\begin{array}{l}\text { Expert Systems with } \\
\text { Applications }\end{array}$ \\
\hline [182] & Metabolic & Support Vector Machine & BMC Medical Imaging \\
\hline [183] & Cancer & Neural Network & $\begin{array}{l}\text { Expert Systems with } \\
\text { Applications }\end{array}$ \\
\hline [184] & Cardiovascular & Neural Network & $\begin{array}{l}\text { Computer Methods and } \\
\text { Programs in Biomedicine }\end{array}$ \\
\hline
\end{tabular}


Table 9 (continued)

\begin{tabular}{|c|c|c|c|}
\hline Paper & Organic system & Algorithm(s) & Outlet \\
\hline [133] & Cancer & Neural Network & $\begin{array}{l}\text { International Conference } \\
\text { on BioMedical Engineer- } \\
\text { ing and Informatics }\end{array}$ \\
\hline$[185]$ & Cardiovascular & Neural Network & $\begin{array}{l}\text { Journal of Cardiovascular } \\
\text { Disease Research }\end{array}$ \\
\hline [186] & Cardiovascular & Neural Network & $\begin{array}{l}\text { Journal of Medical Sys- } \\
\text { tems }\end{array}$ \\
\hline [187] & Cardiovascular & Others & $\begin{array}{l}\text { The 8th International Con- } \\
\text { ference on Cyber and IT } \\
\text { Service Management }\end{array}$ \\
\hline [108] & Cardiovascular & Neural Network & IEEE Access \\
\hline [79] & Gastrointestinal & Decision Tree, Others & $\begin{array}{l}\text { Artificial Intelligence in } \\
\text { Medicine }\end{array}$ \\
\hline [105] & Cancer & Neural Network & $\begin{array}{l}\text { International Conference } \\
\text { on Knowledge Discovery } \\
\text { and Data Mining }\end{array}$ \\
\hline$[56]$ & Cancer & $\begin{array}{l}\text { Decision Tree, Logistic Regres- } \\
\text { sion, Nearest Neighbor, } \\
\text { Neural Network, Support Vector } \\
\text { Machine }\end{array}$ & $\begin{array}{l}\text { Future Generation Com- } \\
\text { puter Systems }\end{array}$ \\
\hline [188] & Gastrointestinal & Neural Network & $\begin{array}{l}\text { Journal of Medical Sys- } \\
\text { tems }\end{array}$ \\
\hline [189] & Cancer & Neural Network & $\begin{array}{l}\text { Journal of Medical Sys- } \\
\text { tems }\end{array}$ \\
\hline [99] & Dermatological & Random Forest & $\begin{array}{l}\text { International Journal of } \\
\text { Medical Engineering and } \\
\text { Informatics }\end{array}$ \\
\hline$[190]$ & $\begin{array}{l}\text { Neurological/psychi- } \\
\text { atric }\end{array}$ & $\begin{array}{l}\text { Naive Bayes, Neural Network, } \\
\text { Support Vector Machine, Others }\end{array}$ & $\begin{array}{l}\text { International Journal of } \\
\text { Systems Science }\end{array}$ \\
\hline [123] & Pediatric & $\begin{array}{l}\text { Decision Tree, Logistic Regres- } \\
\text { sion, Naive Bayes, Random For- } \\
\text { est, Support Vector Machine }\end{array}$ & $\begin{array}{l}\text { Journal of the American } \\
\text { Medical Informatics } \\
\text { Association }\end{array}$ \\
\hline [191] & $\begin{array}{l}\text { Neurological/psychi- } \\
\text { atric }\end{array}$ & Neural Network & $\begin{array}{l}\text { Artificial Intelligence and } \\
\text { Applications }\end{array}$ \\
\hline [151] & Pediatric & Neural Network & Information Sciences \\
\hline [109] & Pediatric & Neural Network & $\begin{array}{l}\text { Computers and Electrical } \\
\text { Engineering }\end{array}$ \\
\hline [55] & $\begin{array}{l}\text { Neurological/psychi- } \\
\text { atric }\end{array}$ & Logistic Regression & $\begin{array}{l}\text { Expert Systems with } \\
\text { Applications }\end{array}$ \\
\hline [192] & Urogenital & $\begin{array}{l}\text { Nearest Neighbor, Support Vector } \\
\text { Machine }\end{array}$ & $\begin{array}{l}\text { International Journal of } \\
\text { Intelligent Systems and } \\
\text { Applications }\end{array}$ \\
\hline$[66]$ & Dermatological & Deep Neural Network & $\begin{array}{l}\text { Computer Vision and Pat- } \\
\text { tern Recognition }\end{array}$ \\
\hline [193] & Infectious & Neural Network & $\begin{array}{l}\text { Annual Research \& } \\
\text { Review in Biology }\end{array}$ \\
\hline [194] & Infectious & Neural Network & $\begin{array}{l}\text { Turkish Journal of Engi- } \\
\text { neering }\end{array}$ \\
\hline [195] & Cancer & Neural Network & Information Sciences \\
\hline [196] & Cancer & Neural Network & $\begin{array}{r}\text { Journal of Mechanics in } \\
\text { Medicine and Biology }\end{array}$ \\
\hline [197] & Cardiovascular & Neural Network & $\begin{array}{l}\text { International Conference } \\
\text { on Neural Networks }\end{array}$ \\
\hline [198] & Gastrointestinal & Neural Network & $\begin{array}{l}\text { Journal of Medical Sys- } \\
\text { tems }\end{array}$ \\
\hline [199] & Infectious & Neural network & $\begin{array}{c}\text { International Joint Confer- } \\
\text { ence on Neural Networks }\end{array}$ \\
\hline
\end{tabular}


Table 9 (continued)

\begin{tabular}{|c|c|c|c|}
\hline Paper & Organic system & Algorithm(s) & Outlet \\
\hline [200] & $\begin{array}{l}\text { Neurological/psychi- } \\
\text { atric }\end{array}$ & Support Vector Machine & $\begin{array}{l}\text { International Journal of } \\
\text { Signal and Imaging } \\
\text { Systems Engineering }\end{array}$ \\
\hline [87] & $\begin{array}{l}\text { Neurological/psychi- } \\
\text { atric }\end{array}$ & Support Vector Machine & $\begin{array}{l}\text { Expert Systems with } \\
\text { Applications }\end{array}$ \\
\hline [106] & Gastrointestinal & Support Vector Machine & $\begin{array}{l}\text { Journal of Medical Sys- } \\
\text { tems }\end{array}$ \\
\hline [201] & $\begin{array}{l}\text { Neurological/psychi- } \\
\text { atric }\end{array}$ & $\begin{array}{l}\text { Decision Tree, Random Forest, } \\
\text { Support Vector Machine }\end{array}$ & $\begin{array}{l}\text { International Journal of } \\
\text { Medical Informatics }\end{array}$ \\
\hline$[80]$ & $\begin{array}{l}\text { Neurological/psychi- } \\
\text { atric }\end{array}$ & $\begin{array}{l}\text { Decision Tree, Logistic Regres- } \\
\text { sion, Random Forest, Support } \\
\text { Vector Machine }\end{array}$ & $\begin{array}{l}\text { International Journal of } \\
\text { Medical Informatics }\end{array}$ \\
\hline [114] & Dermatological & Deep Neural Network & $\begin{array}{l}\text { Asian Pacific Journal of } \\
\text { Cancer Prevention }\end{array}$ \\
\hline [202] & Cardiovascular & Neural Network & $\begin{array}{l}\text { International Conference } \\
\text { on Artificial Intelligence }\end{array}$ \\
\hline [203] & Infectious & $\begin{array}{l}\text { Neural Network, Support Vector } \\
\text { Machine }\end{array}$ & $\begin{array}{l}\text { International Association } \\
\text { of Computer Science and } \\
\text { Information Technology }\end{array}$ \\
\hline [204] & Cardiovascular & Neural Network & $\begin{array}{l}\text { International Journal of } \\
\text { Computer Applications }\end{array}$ \\
\hline [205] & Cardiovascular & Support Vector Machine & $\begin{array}{l}\text { International Journal of } \\
\text { Data Mining and Bioin- } \\
\text { formatics }\end{array}$ \\
\hline [206] & Cardiovascular & Neural Network & $\begin{array}{l}\text { International Journal of } \\
\text { Computer Applications }\end{array}$ \\
\hline [95] & Infectious & Support Vector Machine & $\begin{array}{l}\text { Computer Methods and } \\
\text { Programs in Biomedicine }\end{array}$ \\
\hline [113] & Cancer & Support Vector Machine & $\begin{array}{l}\text { International Conference } \\
\text { on Neural Networks }\end{array}$ \\
\hline [148] & $\begin{array}{l}\text { Neurological/psychi- } \\
\text { atric }\end{array}$ & $\begin{array}{l}\text { Decision Tree, Neural Network, } \\
\text { Support Vector Machine }\end{array}$ & Medical Hypotheses \\
\hline [81] & $\begin{array}{l}\text { Neurological/psychi- } \\
\text { atric }\end{array}$ & Convolutional Neural Network & $\begin{array}{l}\text { International Confer- } \\
\text { ence on Automation \& } \\
\text { Computing }\end{array}$ \\
\hline [207] & Infectious & Support Vector Machine & $\begin{array}{l}\text { International Conference } \\
\text { on Information Systems } \\
\text { Design and Intelligent } \\
\text { Applications }\end{array}$ \\
\hline [96] & Dermatological & Support Vector Machine & $\begin{array}{l}\text { Expert Systems with } \\
\text { Applications }\end{array}$ \\
\hline [208] & Gastrointestinal & Nearest Neighbor, Others & $\begin{array}{l}\text { International Journal of } \\
\text { Healthcare Information } \\
\text { Systems and Informatics }\end{array}$ \\
\hline [117] & Gastrointestinal & Support Vector Machine & $\begin{array}{l}\text { International Journal of } \\
\text { Healthcare Information } \\
\text { Systems and Informatics }\end{array}$ \\
\hline [209] & Gastrointestinal & Nearest Neighbor & $\begin{array}{l}\text { Intelligent Systems Tech- } \\
\text { nologies and Applica- } \\
\text { tions }\end{array}$ \\
\hline [210] & Gastrointestinal & Decision Tree & $\begin{array}{l}\text { International Journal of } \\
\text { Engineering and Tech- } \\
\text { nology }\end{array}$ \\
\hline [4] & Infectious & Nearest Neighbor & Expert Systems \\
\hline
\end{tabular}


Table 9 (continued)

\begin{tabular}{|c|c|c|c|}
\hline Paper & Organic system & Algorithm(s) & Outlet \\
\hline [211] & Pediatric & Neural Network & $\begin{array}{l}\text { International Conference } \\
\text { on Bio Inspired Models } \\
\text { of Network, Information } \\
\text { and Computing Systems }\end{array}$ \\
\hline [212] & Gastrointestinal & Neural Network & $\begin{array}{l}\text { International Conference } \\
\text { on Emerging Trends \& } \\
\text { Innovation }\end{array}$ \\
\hline [213] & Gastrointestinal & Convolutional Neuronal Networks & $\begin{array}{l}\text { International Journal of } \\
\text { Molecular Sciences }\end{array}$ \\
\hline [132] & Cancer & Random Forest & $\begin{array}{l}\text { International Journal of } \\
\text { Performability Engineer- } \\
\text { ing }\end{array}$ \\
\hline [214] & $\begin{array}{l}\text { Neurological/psychi- } \\
\text { atric }\end{array}$ & Neural Network & $\begin{array}{l}\text { Molecular Imaging and } \\
\text { Biology }\end{array}$ \\
\hline [121] & Gastrointestinal & $\begin{array}{l}\text { Decision Tree, Naive Bayes, Near- } \\
\text { est Neighbor, Neural Network, } \\
\text { Support Vector Machine }\end{array}$ & $\begin{array}{l}\text { International Journal of } \\
\text { Medical Informatics }\end{array}$ \\
\hline [215] & $\begin{array}{l}\text { Neurological/psychi- } \\
\text { atric }\end{array}$ & Random Forest & $\begin{array}{l}\text { Machine Learning and } \\
\text { Applications: An Inter- } \\
\text { national Journal }\end{array}$ \\
\hline [216] & Dermatological & Convolutional Neural Network & $\begin{array}{l}\text { Journal of Mechanics of } \\
\text { Continua and Mathemat- } \\
\text { ical Sciences }\end{array}$ \\
\hline [217] & Cardiovascular & Random Forest & $\begin{array}{l}\text { International Journal of } \\
\text { Advance Research in } \\
\text { Science and Engineering }\end{array}$ \\
\hline [124] & Gastrointestinal & Convolutional Neural Network & $\begin{array}{l}\text { Journal of Mechanics of } \\
\text { Continua and Mathemat- } \\
\text { ical Sciences }\end{array}$ \\
\hline [88] & Cancer & Neural Network & Decision Support Systems \\
\hline [100] & $\begin{array}{l}\text { Neurological/psychi- } \\
\text { atric }\end{array}$ & $\begin{array}{l}\text { Convolutional Neural Network, } \\
\text { Recurrent Neural Network }\end{array}$ & IET Research Journals \\
\hline [218] & Cancer & Support Vector Machine & IEEE Access \\
\hline [138] & Dermatological & Support Vector Machine & $\begin{array}{l}\text { Expert Systems with } \\
\text { Applications }\end{array}$ \\
\hline [219] & Metabolic & $\begin{array}{l}\text { Nearest Neighbor, Support Vector } \\
\text { Machine }\end{array}$ & $\begin{array}{l}\text { Microscopy Research and } \\
\text { Technique }\end{array}$ \\
\hline [220] & Cardiovascular & Neural Network & $\begin{array}{l}\text { Medical \& Biological } \\
\text { Engineering \& Comput- } \\
\text { ing }\end{array}$ \\
\hline [107] & Cancer & Neural Network & Chinese Medical Journal \\
\hline [221] & Gastrointestinal & $\begin{array}{l}\text { Neural Network, Support Vector } \\
\text { Machine }\end{array}$ & $\begin{array}{l}\text { International Journal of } \\
\text { Research in Engineering }\end{array}$ \\
\hline [97] & Metabolic & Neural Network & Neurocomputing \\
\hline [222] & Infectious & Others & $\begin{array}{l}\text { International Journal of } \\
\text { Medical Informatics }\end{array}$ \\
\hline
\end{tabular}




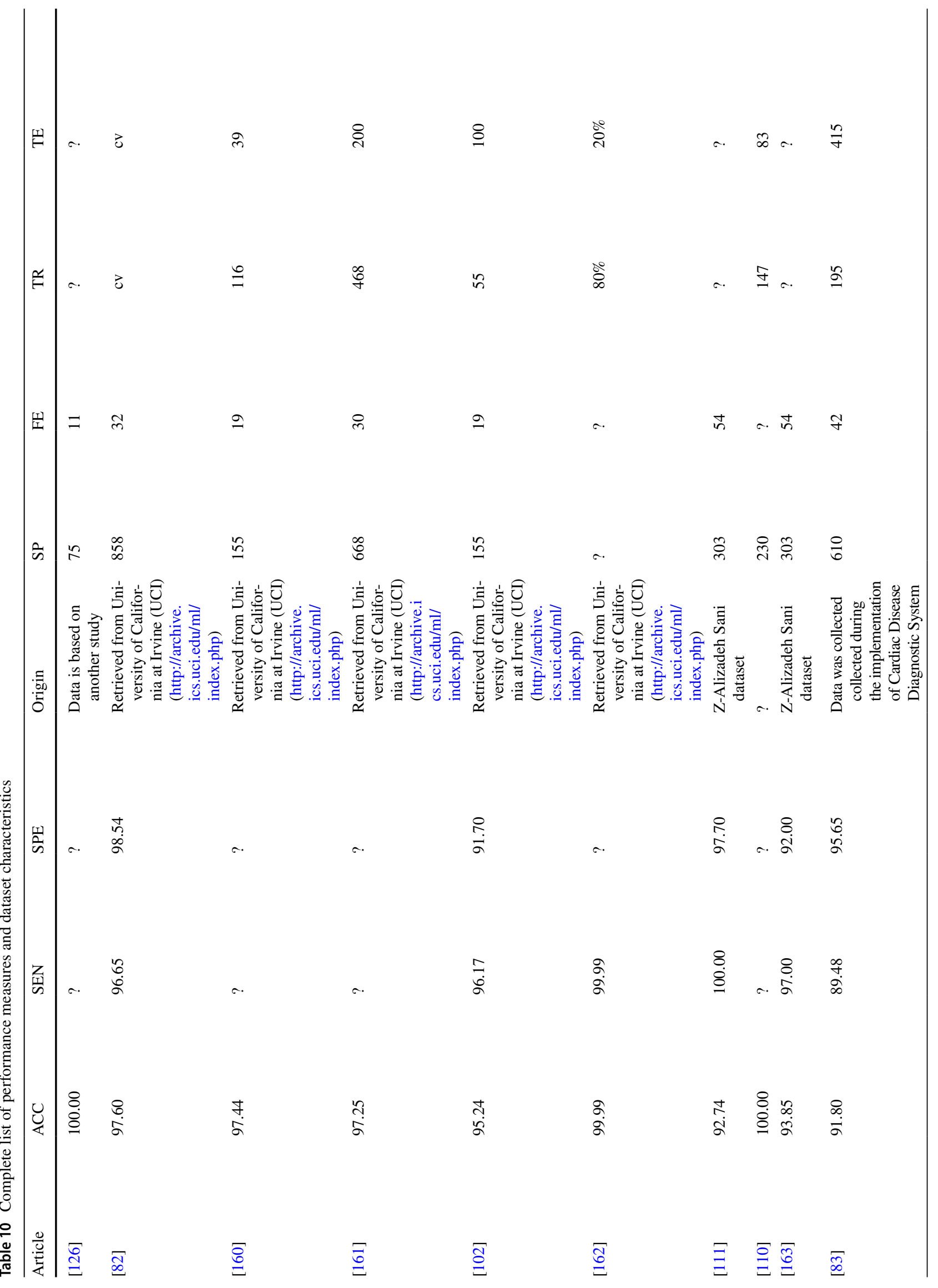




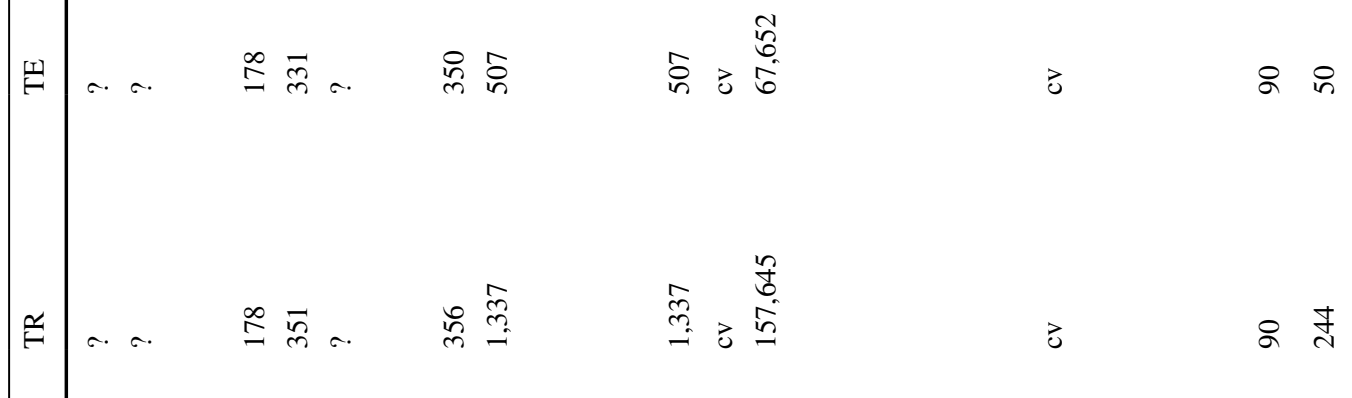

四

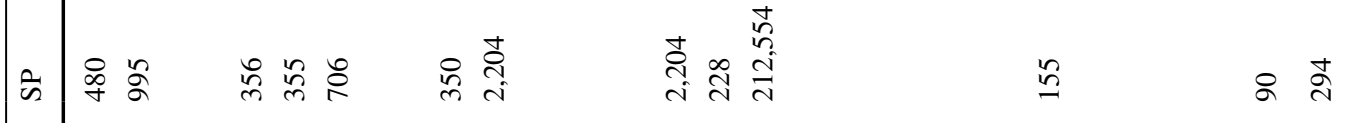

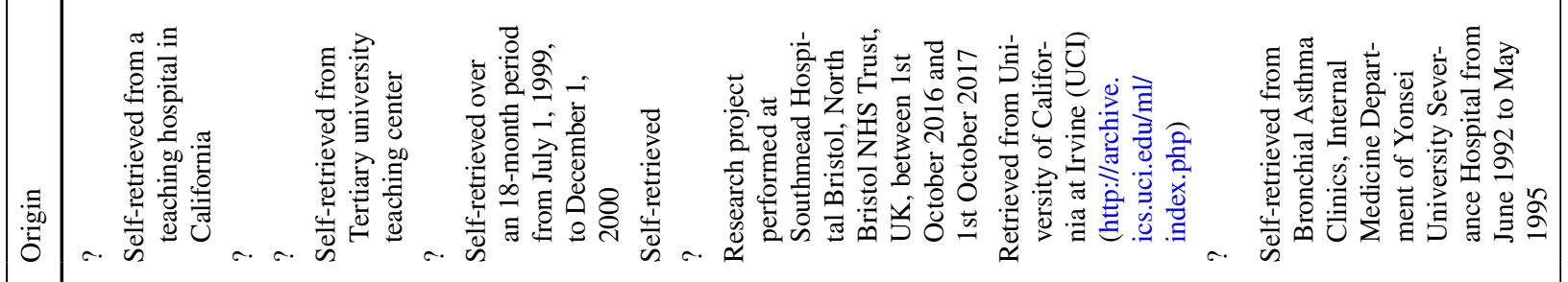

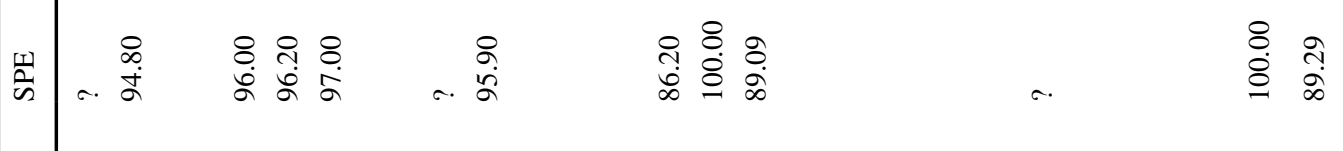

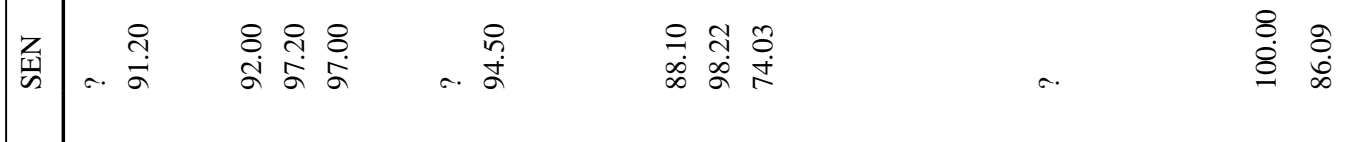

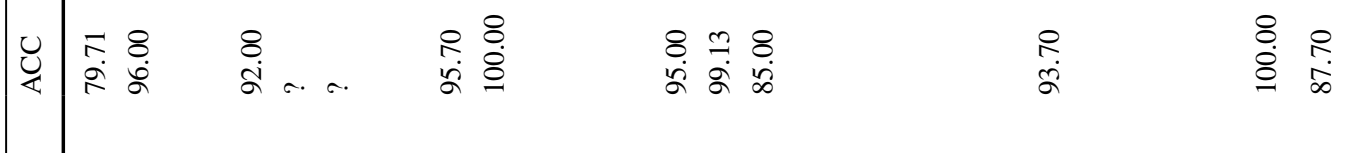

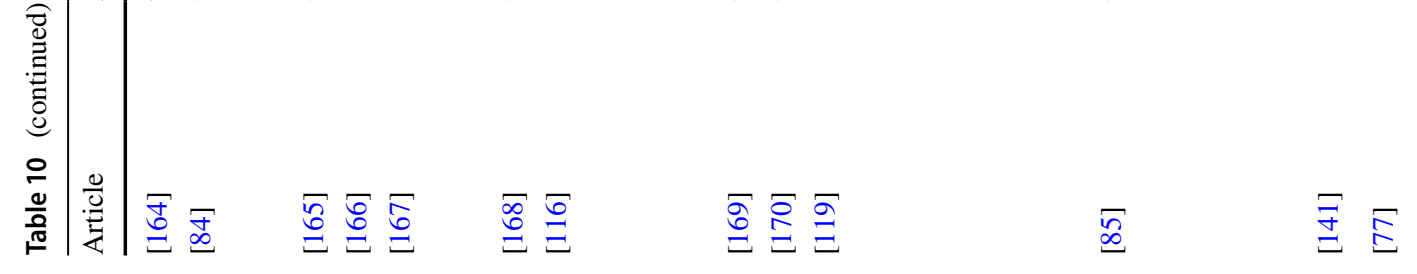




\begin{tabular}{|c|c|c|c|c|c|c|}
\hline Ir & $8 \equiv$ 只 & 声 & $\underset{\nearrow}{\simeq}$ & a. a. $=$ & $F$ & 3 \\
\hline$\cong$ & 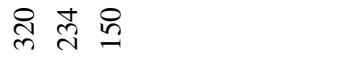 & ปิ & $\infty$ & a. a. ç & $\ddot{n}$ & 3 \\
\hline 歩 & न. ले न. & ส & & a. a. $\approx$ & $\approx$ & a. \\
\hline$\tilde{\omega}$ & ণิ & $\hat{\circ}$ & 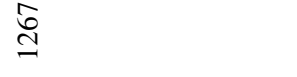 & $\bar{\infty} \stackrel{n}{n}$ & $\stackrel{+}{q}$ & a. \\
\hline 苛 & 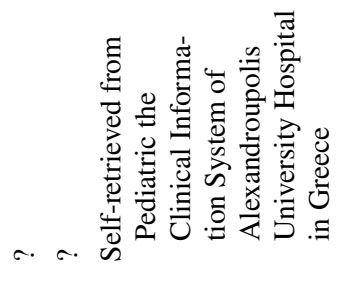 & 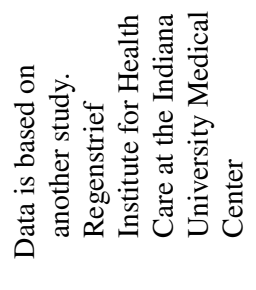 & 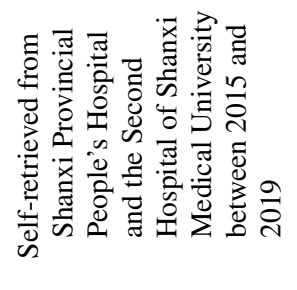 & a. a. & 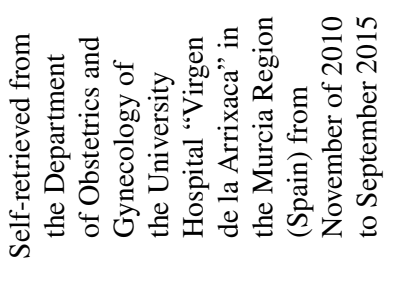 & 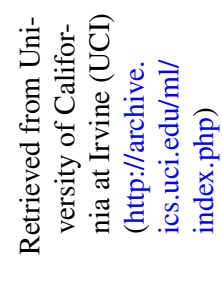 \\
\hline 空 & $\begin{array}{lll}n & 0 & \\
n & n & \\
0 & 0 & \\
0 & \infty\end{array}$ & $\frac{8}{a}$ & a. & 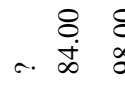 & $\begin{array}{l}8 \\
\infty \\
\infty \\
\infty\end{array}$ & $\stackrel{\text { a }}{\text { s. }}$ \\
\hline 葸 & 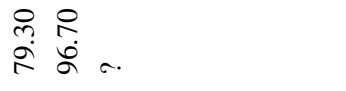 & $\underset{\infty}{\infty}$ & $a$. & ๙. $\begin{array}{rl}8 & 8 \\
0 & 8\end{array}$ & \& & ڤ̆ \\
\hline U & $\begin{array}{ll} & 8 \\
\circ . & . \\
\infty\end{array}$ & a. & $\stackrel{\infty}{\stackrel{+}{+}}$ & 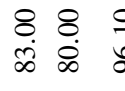 & $\frac{\circ}{2}$ & 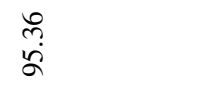 \\
\hline 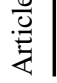 & $\stackrel{\sqrt[\Im]{\Xi}}{\Xi} \stackrel{\Xi}{\Xi}$ & $\Xi$ & $\stackrel{\widetilde{N}}{\Xi}$ & $\stackrel{\infty}{\Xi} \stackrel{\Xi}{\Xi} \Xi$ & 里 & $\stackrel{\infty}{\Xi}$ \\
\hline
\end{tabular}




\begin{tabular}{|c|c|c|c|c|c|c|c|c|c|c|}
\hline 납 & a. & $\underline{0}$ & 3 & $\infty 0$ & & 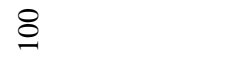 & $m$ & r. & a. a. $\stackrel{\infty}{\circ}$ & $\stackrel{\mathfrak{F}}{\stackrel{f}{f}}$ \\
\hline$\stackrel{x}{F}$ & a. & ह & 3 & $\approx 0$ & & 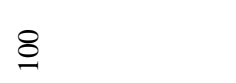 & $\stackrel{\infty}{\infty}$ & $a$. & a. a. $\stackrel{\infty}{a}$ & $\stackrel{n}{\stackrel{n}{-}}$ \\
\hline 正 & 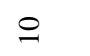 & $=$ & $i n$ & a. o & a. & ๙ิ & $m$ & $\stackrel{d}{d}$ & $\stackrel{0}{-}$. & $\mathscr{F}$ \\
\hline के & $\exists$ & f & 草 & $\begin{array}{l}\hat{\imath} \\
\dot{m}\end{array}$ & & $\stackrel{+}{2}$ & $\stackrel{n}{\sim}$ & $\cong$ & $\stackrel{\infty}{\circ}$.. & $\frac{\text { 票 }}{n^{-1}}$ \\
\hline 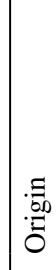 & 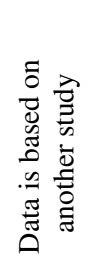 & 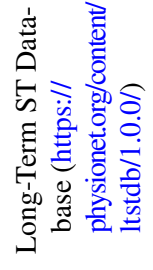 & & 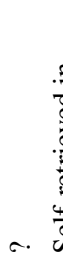 & 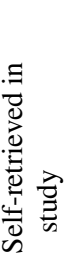 & 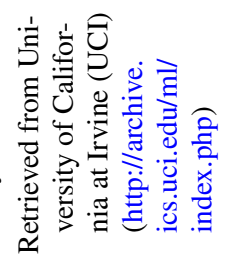 & 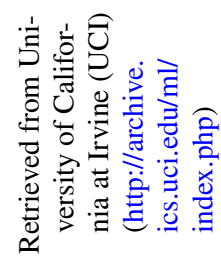 & 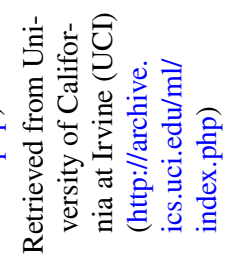 & 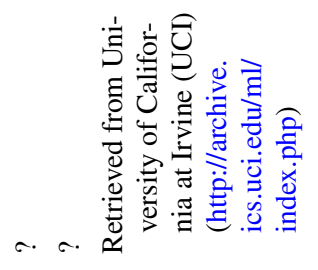 & 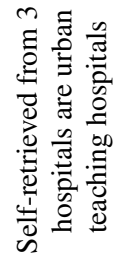 \\
\hline in & $\begin{array}{l}\text { ลุ } \\
\text { ลे }\end{array}$ & $\begin{array}{l}\stackrel{8}{0} \\
\stackrel{\Xi}{0}\end{array}$ & $\underset{⿱}{\infty}$ & $\begin{array}{ll}\infty & 8 \\
\dot{\vec{j}} & 0 \\
\infty & 0\end{array}$ & $\begin{array}{c}8 \\
\infty \\
\infty \\
\infty\end{array}$ & $\begin{array}{l}8 \\
\stackrel{8}{0}\end{array}$ & a. & $\begin{array}{l}8 \\
\stackrel{\circ}{a}\end{array}$ & 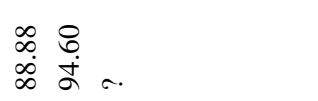 & $\begin{array}{l}8 \\
\dot{+}\end{array}$ \\
\hline 至 & $\begin{array}{l}8 \\
\stackrel{8}{0}\end{array}$ & $\underset{\substack{q \\
\infty}}{\infty}$ & $\begin{array}{l}\hat{\lambda} \\
\infty \\
\infty\end{array}$ & 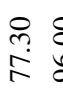 & $\begin{array}{l}8 \\
\text { \& }\end{array}$ & $\stackrel{8}{\circ}$ & a. & ले & 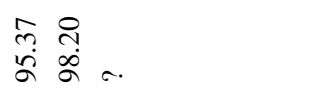 & $\begin{array}{l}8 \\
+ \\
\end{array}$ \\
\hline 4 & $\begin{array}{l}\text { m. } \\
\text { à }\end{array}$ & $\begin{array}{l}\text { तิ } \\
\text { ă }\end{array}$ & $\underset{\substack{\vec{i} \\
\text { J }}}{=}$ & $\stackrel{\infty}{\stackrel{\infty}{\infty} .}$ & & $\begin{array}{l}8 \\
\stackrel{0}{0}\end{array}$ & $\begin{array}{l}\dot{B} \\
\infty \\
\infty\end{array}$ & $\stackrel{8}{\circ}$ & 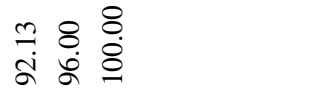 & $\begin{array}{l}8 \\
\infty \\
\infty\end{array}$ \\
\hline & $\stackrel{\widetilde{\Xi}}{\Xi}$ & $\begin{array}{l}\overline{0} \\
\stackrel{9}{\Xi}\end{array}$ & 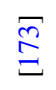 & $\stackrel{\Xi}{\Xi}$ & & $\stackrel{\bar{g}}{\Xi}$ & $\stackrel{\bar{o}}{ \pm}$ & $\stackrel{\bar{a}}{\varrho}$ & 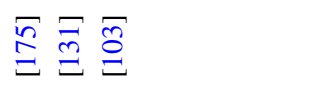 & $\stackrel{\Xi}{\Xi}$ \\
\hline
\end{tabular}




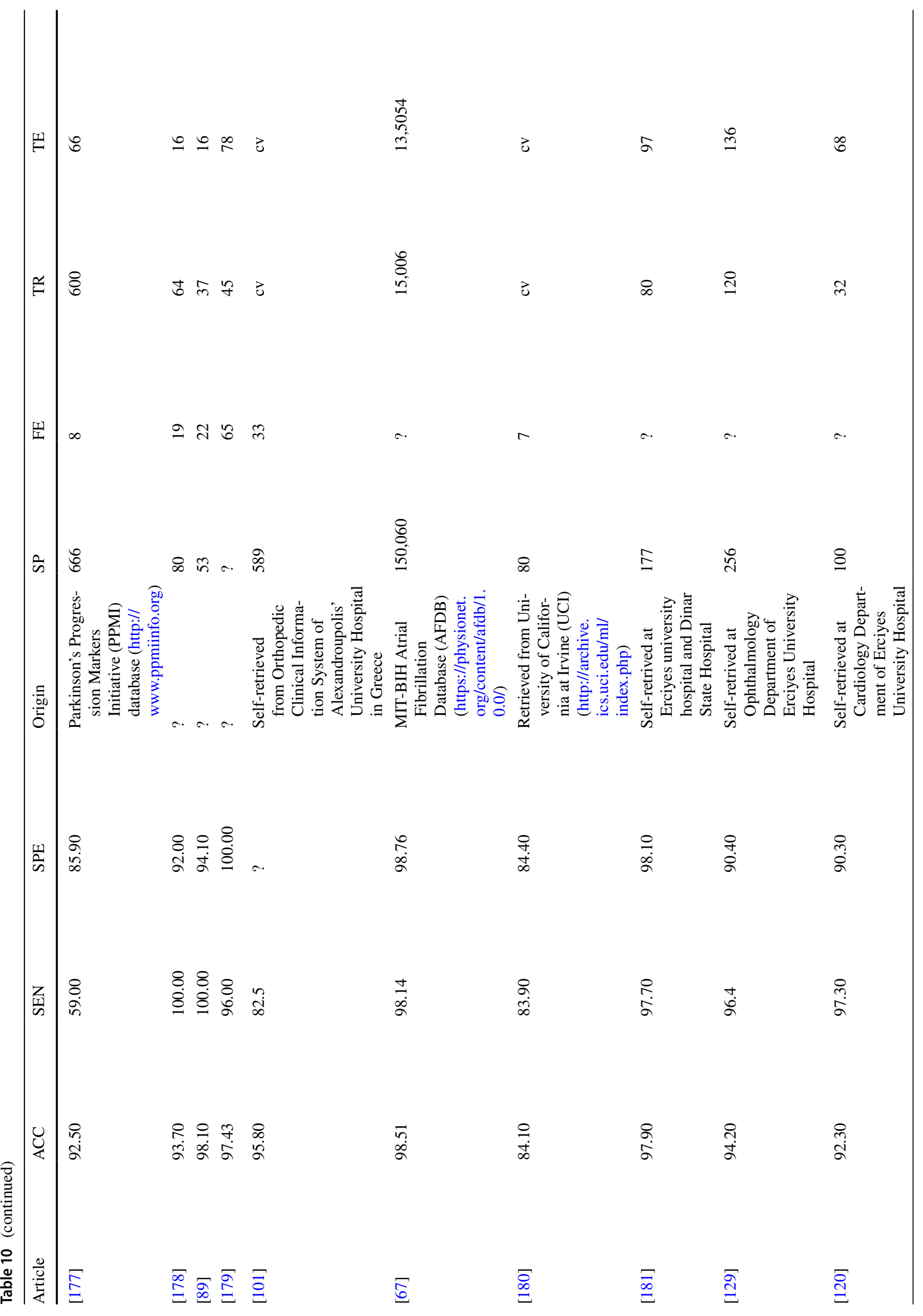




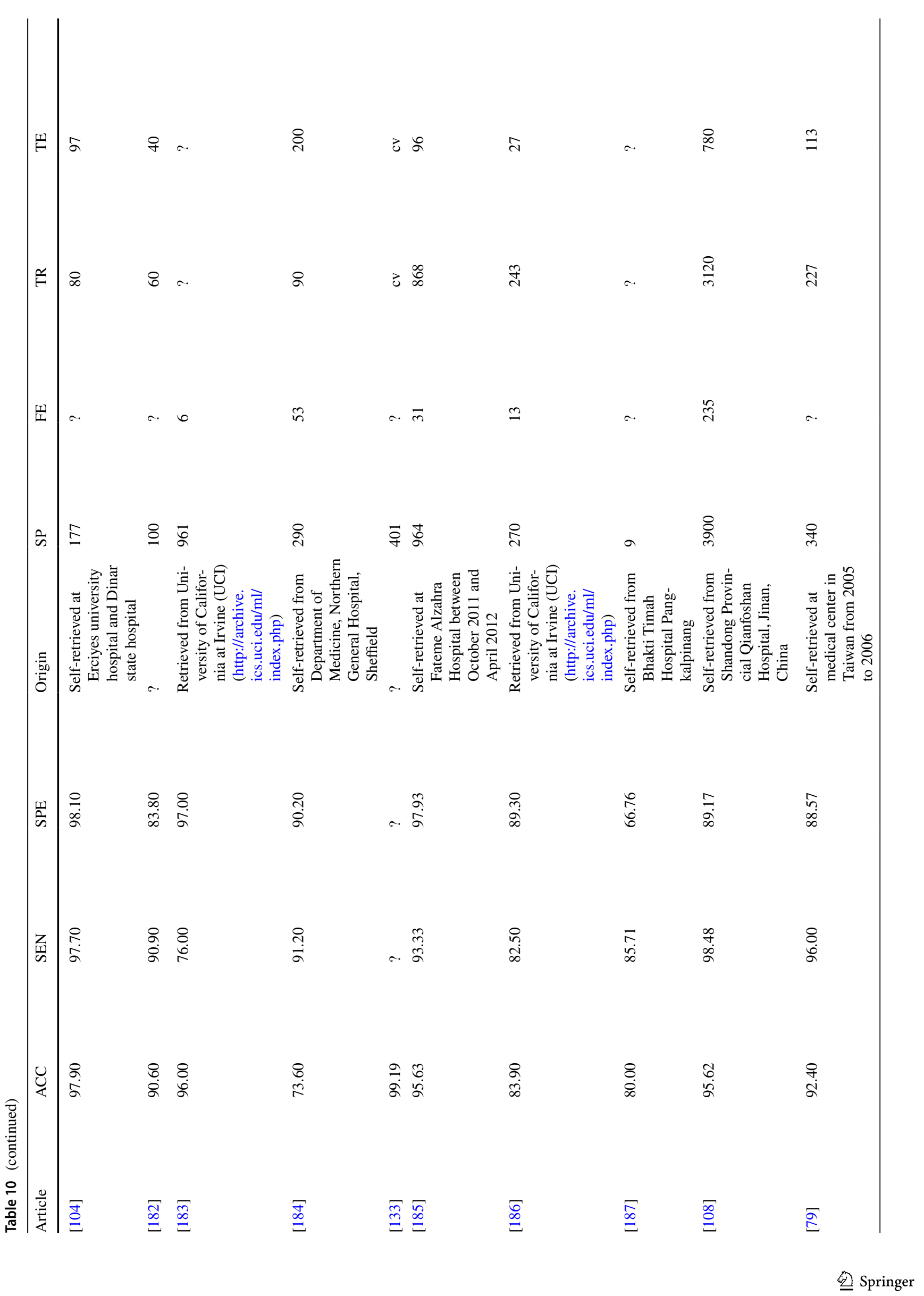




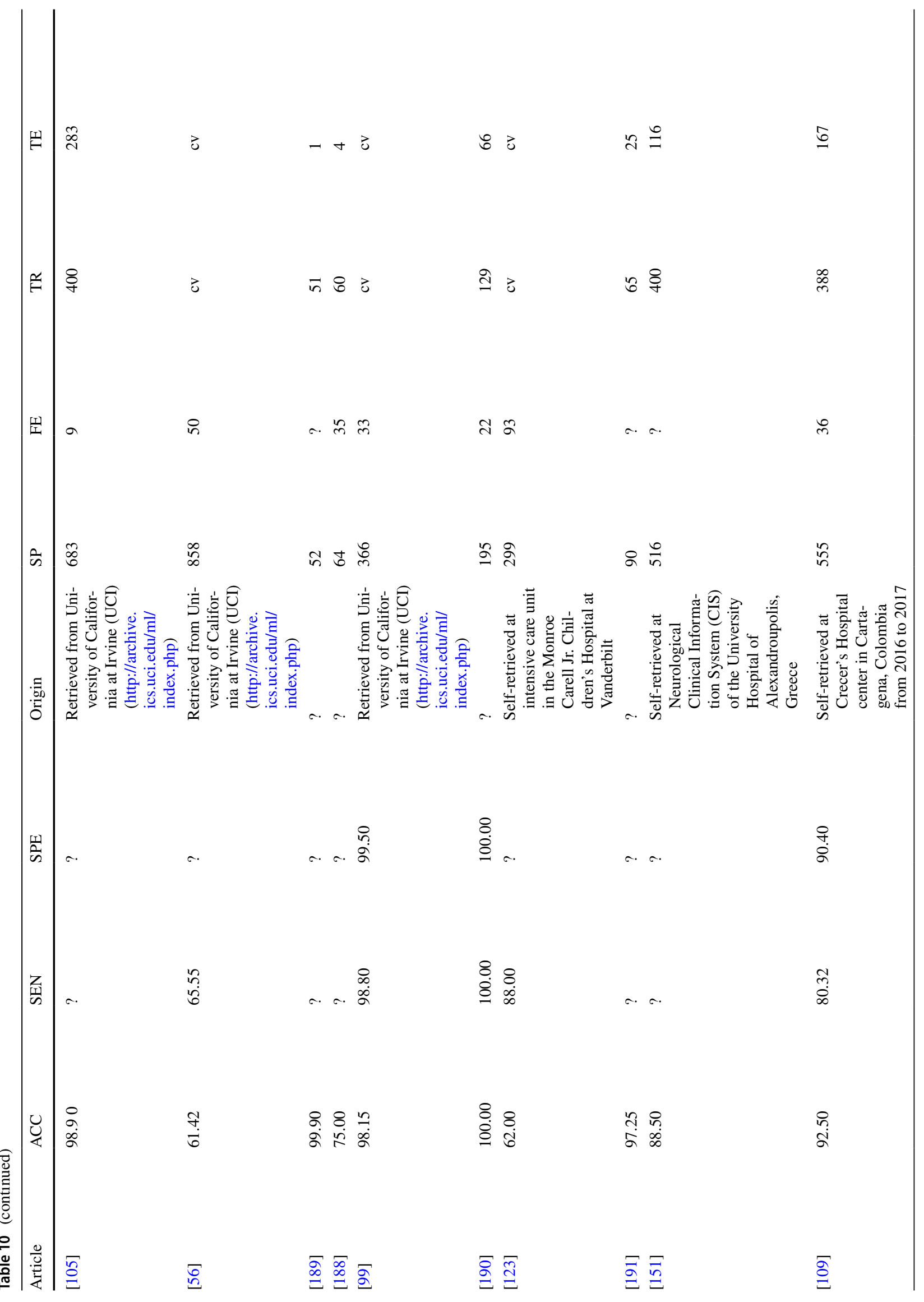




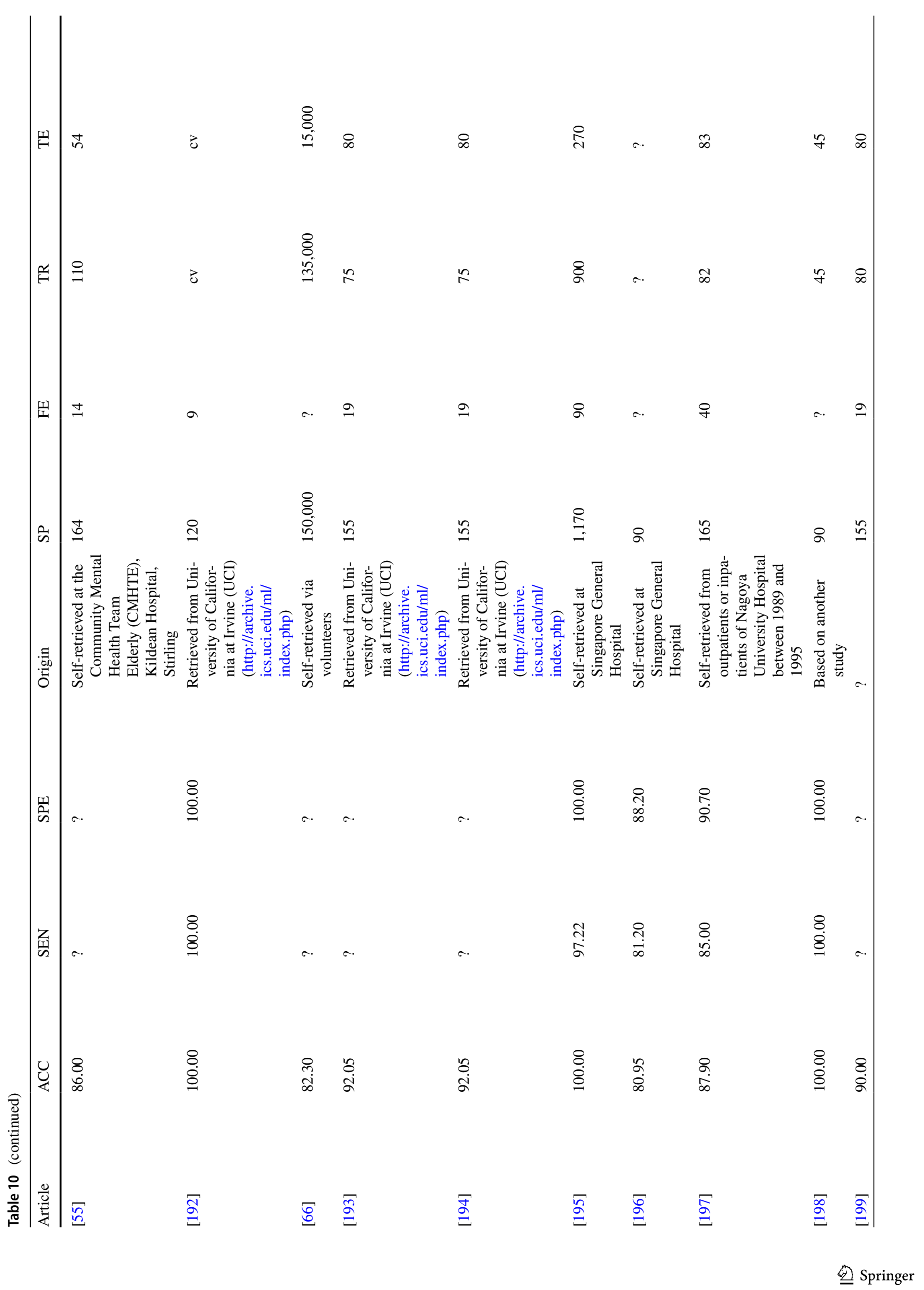




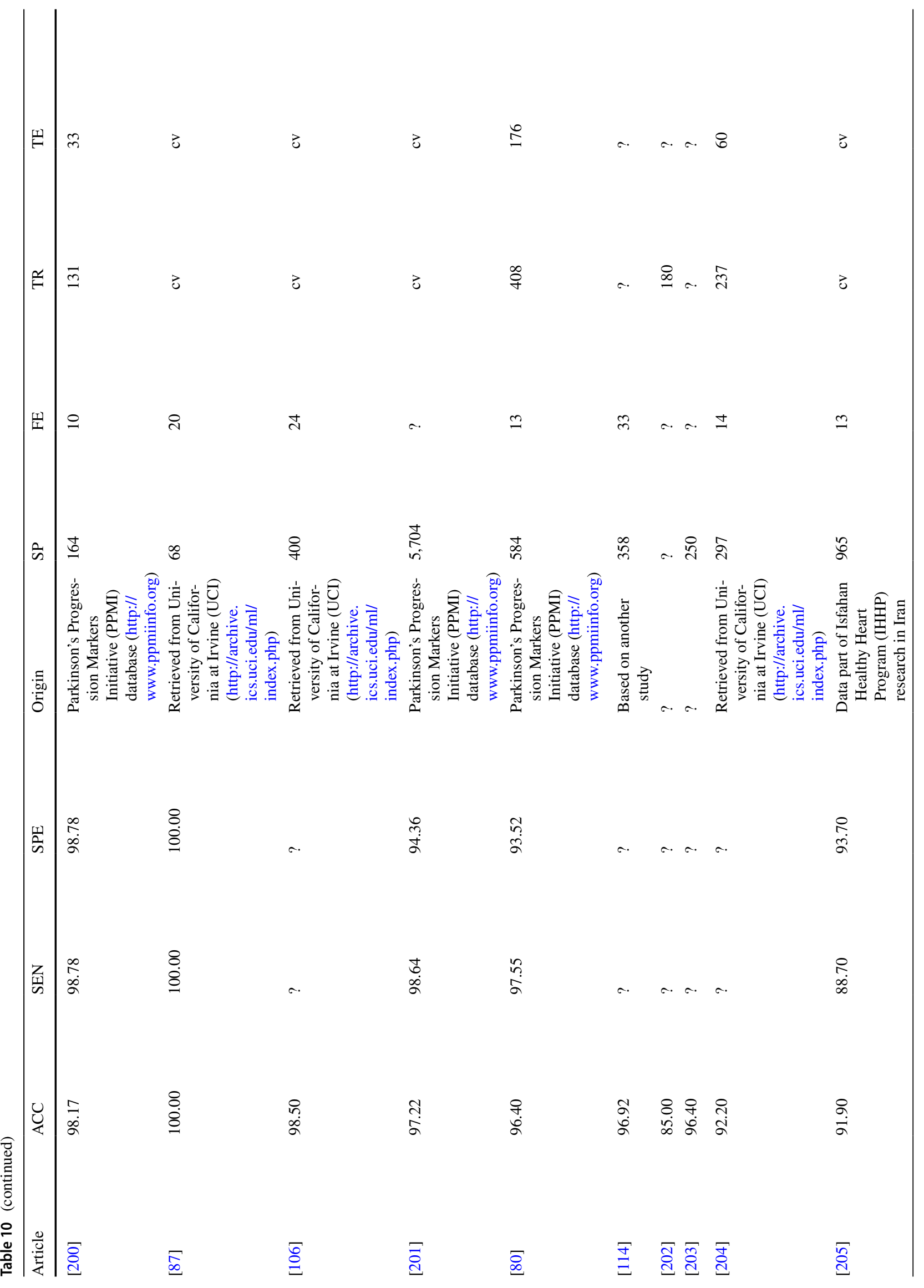




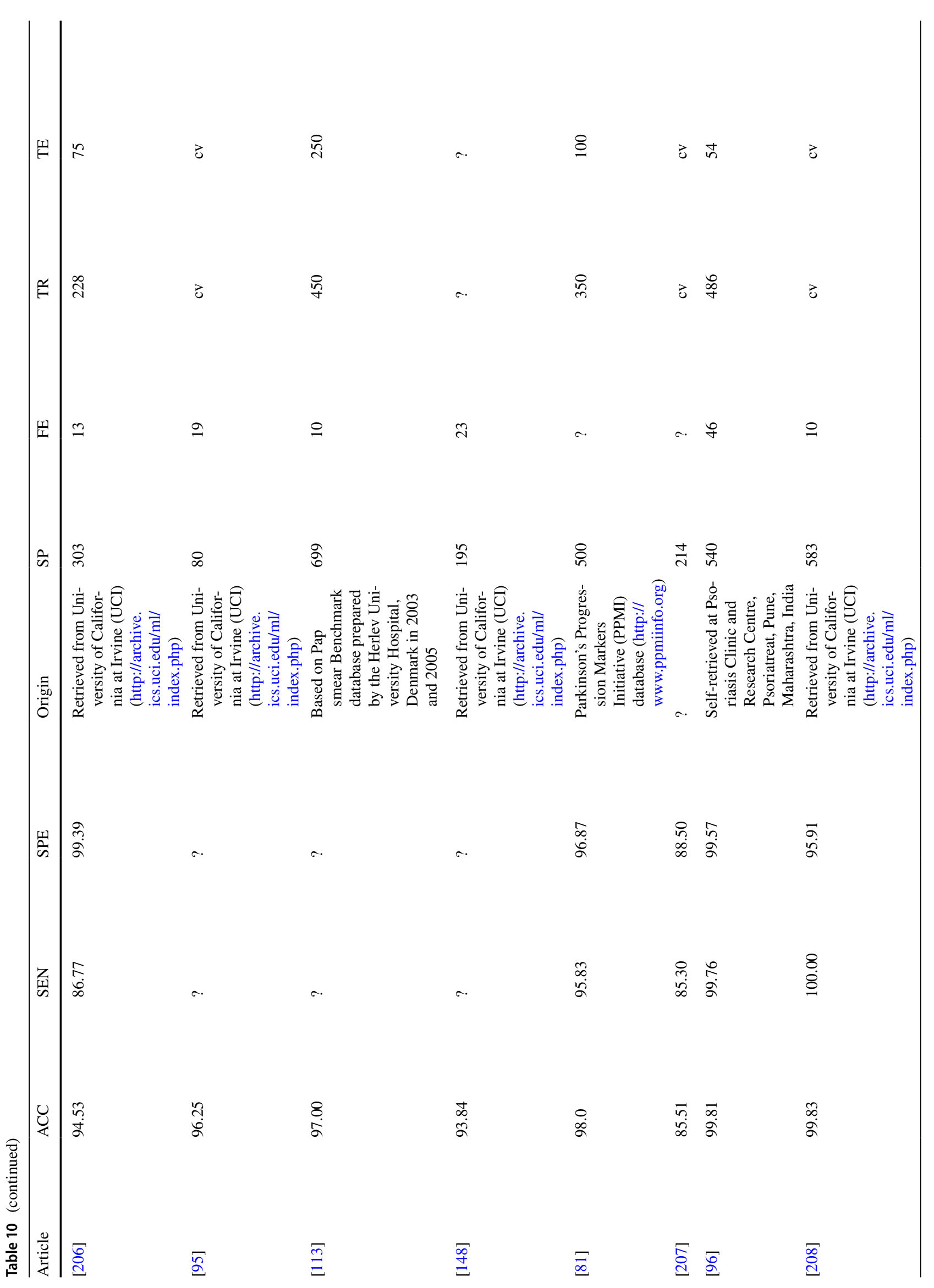




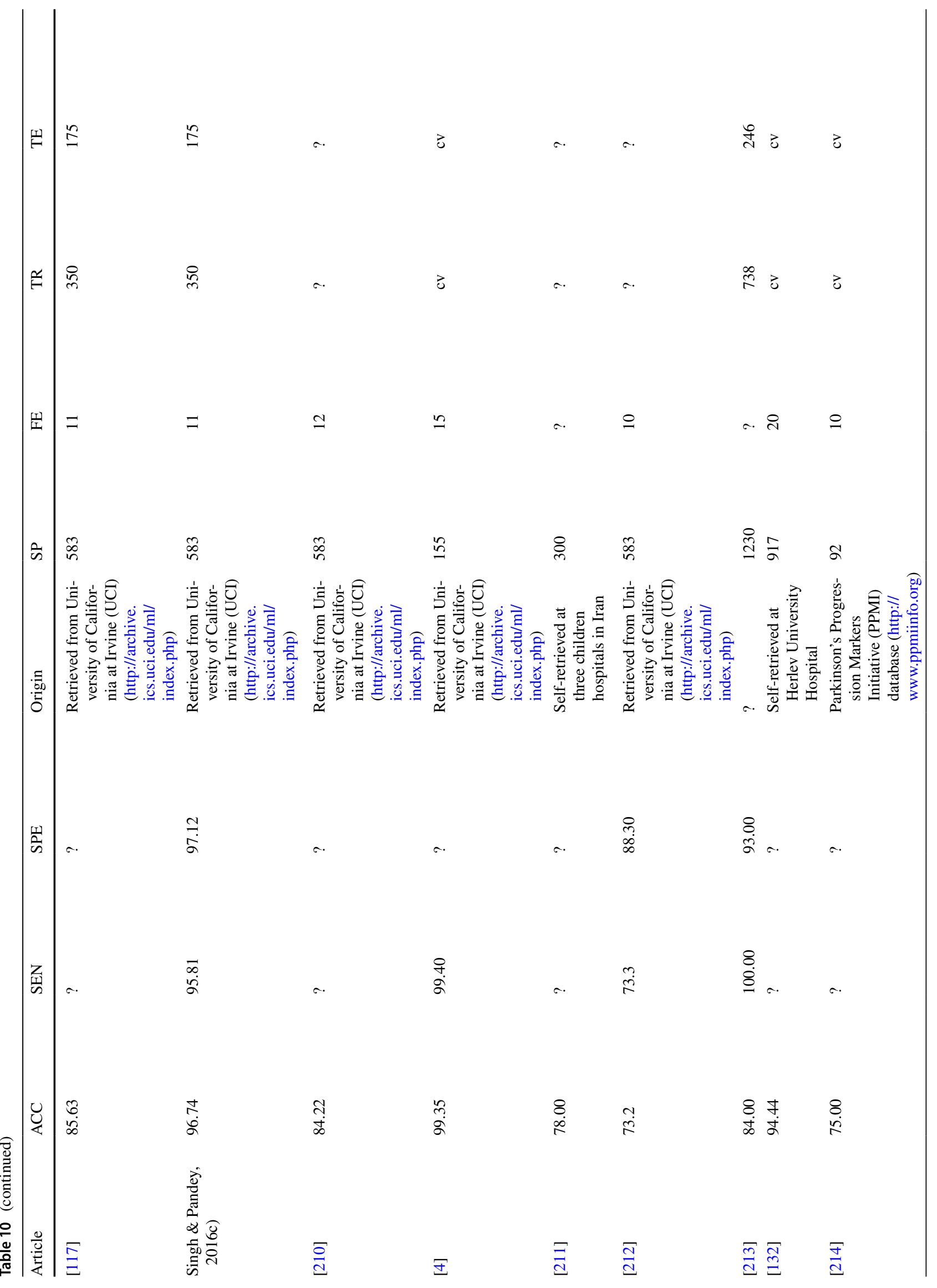




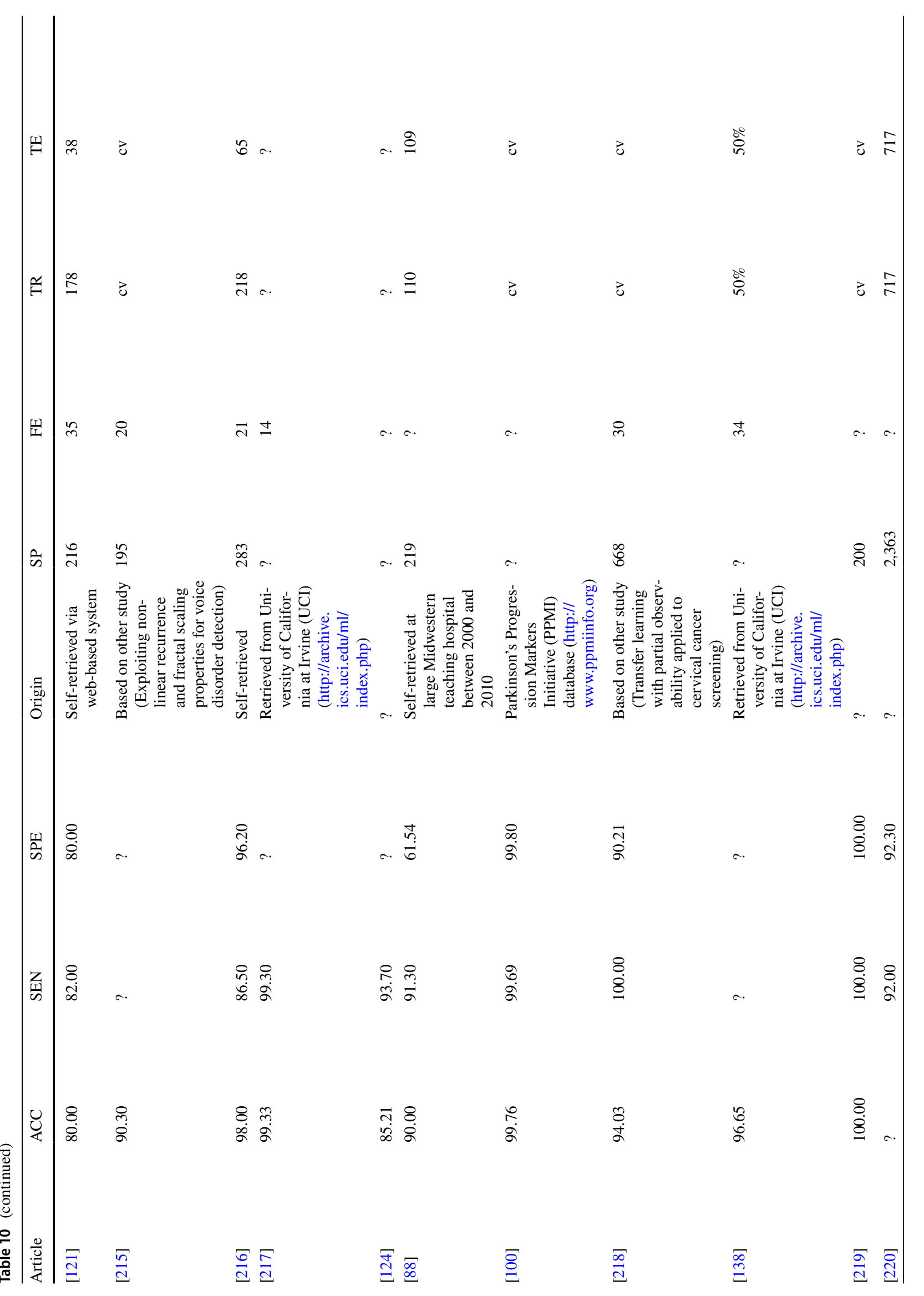


72

Health and Technology (2021) 11:693-731

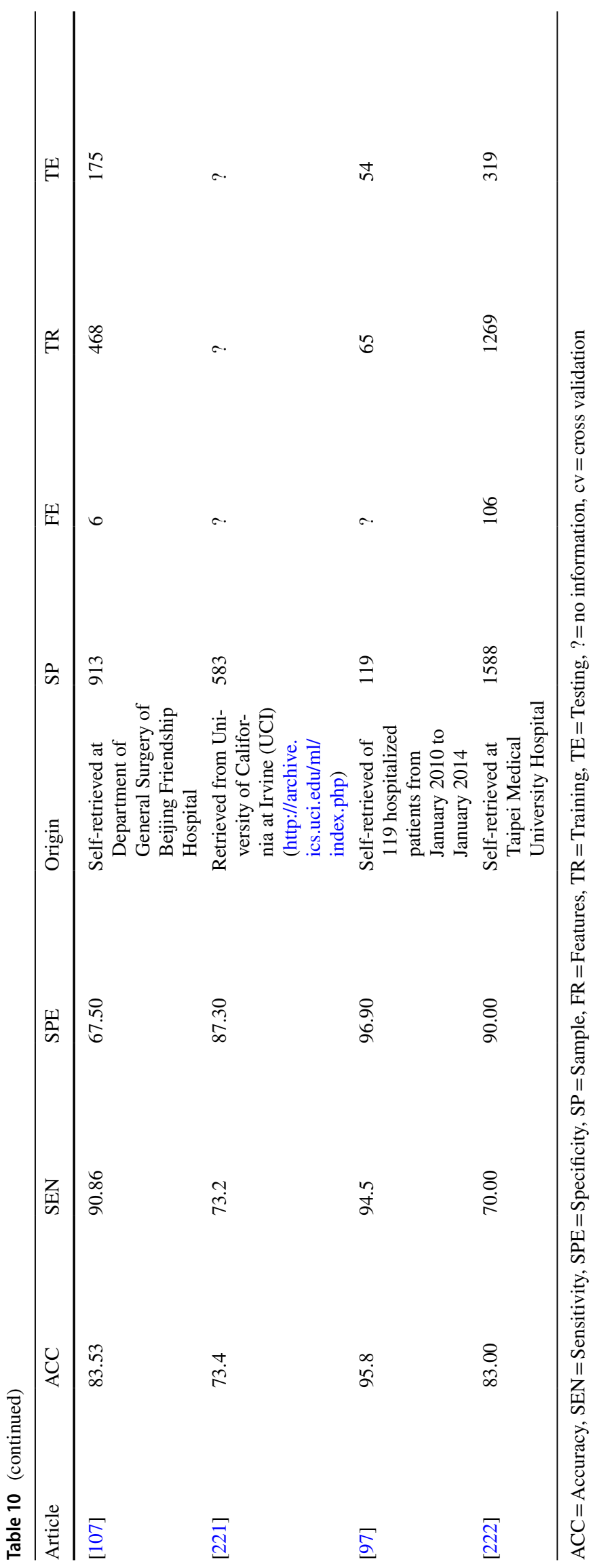

Springer 
Author contributions Each author contributed equally.

Funding Open Access funding enabled and organized by Projekt DEAL. This research did not receive any specific grant from funding agencies in the public, commercial, or not-for profit sectors.

Open Access This article is licensed under a Creative Commons Attribution 4.0 International License, which permits use, sharing, adaptation, distribution and reproduction in any medium or format, as long as you give appropriate credit to the original author(s) and the source, provide a link to the Creative Commons licence, and indicate if changes were made. The images or other third party material in this article are included in the article's Creative Commons licence, unless indicated otherwise in a credit line to the material. If material is not included in the article's Creative Commons licence and your intended use is not permitted by statutory regulation or exceeds the permitted use, you will need to obtain permission directly from the copyright holder. To view a copy of this licence, visit http://creativecommons.org/licenses/by/4.0/.

\section{References}

1. Menschner P, Prinz A, Koene P, Köbler F, Altmann M, Krcmar $\mathrm{H}$, et al. Reaching into patients' homes - Participatory designed AAL services: The case of a patient-centered nutrition tracking service. Electron Mark. 2011;21:63-76. https://doi.org/10.1007/ s12525-011-0050-6.

2. Wears RL, Berg M. Computer Technology and Clinical Work. J Am Med Assoc. 2005;293:1261-3. https://doi.org/10.1001/jama. 293.10.1261.

3. Rosen MA, DiazGranados D, Dietz AS, Benishek LE, Thompson D, Pronovost PJ, et al. Teamwork in Healthcare: Key Discoveries Enabling Safer, High- Quality Care. Am Psychol [Internet]. 2018;73:433-50. https://doi.org/10.1037/amp0000298.

4. Singh A, Mehta JC, Anand D, Nath P, Pandey B, Khamparia A. An intelligent hybrid approach for hepatitis disease diagnosis: Combining enhanced $\mathrm{k}$-means clustering and improved ensemble learning. Expert Syst [Internet]. 2020;1-13. https://doi.org/ 10.1111/exsy. 12526

5. Laurenzi E, Hinkelmann K, Reimer U, Van Der Merwe A, Sibold P. Endl R. DSML4PTM: A domain-specific modelling language for patient transferal management. ICEIS 2017 - Proc 19th Int Conf Enterp Inf Syst. 2017;3:520-31. https://doi.org/10.5220/ 0006388505200531 .

6. Zwaan L, Singh H. The challenges in defining and measuring diagnostic error. Diagnosis. 2015;2:97-103. https://doi.org/10. 1515/dx-2014-0069.

7. Eigner I, Bodendorf F, Wickramasinghe N. Predicting high-cost patients by machine learning: A case study in an Australian private hospital group. Proc 11th Int Conf Bioinforma Comput Biol BiCOB 2019. 2019. p. 94-103. https://doi.org/10.29007/jw6h.

8. Baerheim A. The diagnostic process in general practice: Has it a two-phase structure? Fam Pract. 2001;18:243-5. https://doi.org/ 10.1093/fampra/18.3.243.

9. Samhan B, Crampton T, Ruane R. The Trajectory of IT in Healthcare at HICSS: A Literature Review, Analysis, and Future Directions. Commun Assoc Inf Syst [Internet]. 2018;43:792845. https://doi.org/10.17705/1CAIS.04341.

10. Balogh EP, Miller BT, R. B. Improving Diagnosis in Health Care. Washington DC: The National Academics Press; 2015.

11. Frick NRJ, Möllmann HL, Mirbabaie M, Stieglitz S. Driving Digital Transformation During a Pandemic: Case Study of Virtual Collaboration in a German Hospital. JMIR Med Informatics [Internet]. 2021;9:e25183. https://doi.org/10.2196/25183.
12. Knijnenburg B, Willemsen M. Inferring Capabilities of Intelligent Agents from Their External Traits. ACM Trans Interact Intell Syst [Internet]. 2016;6:1-25. https://doi.org/10.1145/2963106.

13. Luger E, Sellen A. "Like Having a Really Bad PA": The Gulf between User Expectation and Experience of Conversational Agents. Proc 2016 CHI Conf Hum Factors Comput Syst - CHI '16 [Internet]. 2016. p. 5286-97. https://doi.org/10.1145/2858036. 2858288.

14. Selz D. From electronic markets to data driven insights. Electron Mark Electronic Markets. 2020;30:57-9. https://doi.org/10.1007/ s12525-019-00393-4.

15. Mendling J, Decker G, Hull R, Reijers HA, Weber I. How do Machine Learning, Robotic Process Automation, and Blockchains Affect the Human Factor in Business Process Management? Commun Assoc Inf Syst [Internet]. 2018;297-320. https:// doi.org/10.17705/1CAIS.04319.

16. Mirbabaie M, Stieglitz S, Frick NRJ. Hybrid Intelligence in Hospitals - Towards a Research Agenda for Collaboration. Electron Mark. 2021;forthcoming.

17. Loebbecke C, Sawy OA El, Kankanhalli A, Markus ML, Te'eni V. Artificial Intelligence Meets IS Researchers: Can It Replace Us? Commun Assoc Inf Syst. 2020;47:273-83.

18. Mirbabaie M, Stieglitz S, Brünker F, Hofeditz L, Ross B, Frick NRJ. Understanding Collaboration with Virtual Assistants - The Role of Social Identity and the Extended Self. Bus Inf Syst Eng [Internet]. 2020; https://doi.org/10.1007/s12599-020-00672-x.

19. Frick NRJ, Mirbabaie M, Stieglitz S, Salomon J. Maneuvering through the stormy seas of digital transformation: the impact of empowering leadership on the AI readiness of enterprises. J Decis Syst. 2021;forthcoming. https://doi.org/10.1080/12460125. 2020.1870065

20. Duan Y, Edwards JS, Dwivedi YK. Artificial intelligence for decision making in the era of Big Data - evolution, challenges and research agenda. Int J Inf Manage Elsevier. 2019;48:63-71. https://doi.org/10.1016/j.ijinfomgt.2019.01.021.

21. Rai A, Constantinides P, Sarker S. Editor's Comments: NextGeneration Digital Platforms: Toward Human-AI Hybrids. MIS Q. 2019;43:iii-ix.

22. Krittanawong C, Zhang H, Wang Z, Aydar M, Kitai T. Artificial Intelligence in Precision Cardiovascular Medicine. J Am Coll Cardiol [Internet]. 2017;69:2657-64. https://doi.org/10.1016/j. jacc.2017.03.571.

23. Rech J, Althoff K. Artificial Intelligence and Software Engineering: Status and Future Trends. KI. 2004;18:5-11.

24. Batin M, Turchin A, Markov S, Zhila A, Denkenberger D. Artificial Intelligence in Life Extension: from Deep Learning to Superintelligence. Informatica. 2017;41:401-17.

25. Mitchell T, Cohen W, Hruschka E, Talukdar P, Yang B, Betteridge J, et al. Never-ending learning. Commun ACM [Internet]. 2018;61:103-15. https://doi.org/10.1145/3191513.

26. Diederich S, Brendel A, M Kolbe L. On Conversational Agents in Information Systems Research: Analyzing the Past to Guide Future Work. Proc 14th Int Conf Wirtschaftsinformatik. 2019;1550-64.

27. Preece A, Webberley W, Braines D, Zaroukian E, Bakdash J. Sherlock: Experimental Evaluation of a Conversational Agent for Mobile Information Tasks. IEEE Trans Human-Machine Syst. 2017;47:1017-28. https://doi.org/10.1109/THMS.2017.2700625.

28. Nasirian F, Ahmadian M, Lee OK. AI-Based Voice Assistant Systems: Evaluating from the Interaction and Trust Perspectives. Twenty-third Am Conf Inf Syst. 2017.

29. Dilsizian SE, Siegel EL. Artificial Intelligence in Medicine and Cardiac Imaging: Harnessing Big Data and Advanced Computing to Provide Personalized Medical Diagnosis and Treatment. Curr Cardiol Rep [Internet]. 2014;16:441. https://doi.org/10. 1007/s11886-013-0441-8. 
30. McCracken SS, Edwards JS. Implementing a knowledge management system within an NHS hospital: a case study exploring the roll-out of an electronic patient record (EPR). Knowl Manag Res Pract [Internet]. 2017;15:1-11. https://doi.org/10.1057/kmrp. 2015.7.

31. Neill DB. Using Artificial Intelligence to Improve Hospital Inpatient Care. IEEE Intell Syst [Internet]. 2013;28:92-5. https://doi. org/10.1109/MIS.2013.51.

32. Gnewuch U, Morana S, Maedche A. Towards Designing Cooperative and Social Conversational Agents for Customer Service. Thirty Eighth Int Conf Inf Syst. 2017.

33. Jiang F, Jiang Y, Zhi H, Dong Y, Li H, Ma S, et al. Artificial intelligence in healthcare : past , present and future. 2017;1-14. https://doi.org/10.1136/svn-2017-000101.

34. Rong G, Mendez A, Bou Assi E, Zhao B, Sawan M. Artificial Intelligence in Healthcare: Review and Prediction Case Studies. Engineering [Internet]. Chinese Academy of Engineering; 2020;6:291-301. https://doi.org/10.1016/j.eng.2019.08.015.

35. Frick NR, Brünker F, Ross B, Stieglitz S. Comparison of disclosure/concealment of medical information given to conversational agents or to physicians. Health Informatics J [Internet]. 2021;27:146045822199486. https://doi.org/10.1177/ 1460458221994861 .

36. Rauschert S, Raubenheimer K, Melton PE, Huang RC. Machine learning and clinical epigenetics: A review of challenges for diagnosis and classification. Clin Epigenetics. Clinical Epigenetics; 2020;12. https://doi.org/10.1186/s13148-020-00842-4.

37. Okoli C. A Guide to Conducting a Standalone Systematic Literature Review. Commun Assoc Inf Syst [Internet]. 2015;37:879910. https://doi.org/10.17705/1CAIS.03743.

38. Paré G, Trudel M-C, Jaana M, Kitsiou S. Synthesizing information systems knowledge: A typology of literature reviews. Inf Manag [Internet]. 2015;52:183-99. https://doi.org/10.1016/j.im. 2014.08.008.

39. Grant MJ, Booth A. A typology of reviews: an analysis of 14 review types and associated methodologies. Heal Inf Libr J [Internet]. 2009;26:91-108. https://doi.org/10.1111/j.1471-1842. 2009.00848.x.

40. Ransohoff DF, Feinstein AR. Problems of Spectrum and Bias in Evaluating the Efficacy of Diagnostic Tests. N Engl J Med. 1978;299:926-30.

41. Jutel A. Sociology of diagnosis: A preliminary review. Sociol Heal Illn. 2009;31:278-99. https://doi.org/10.1111/j.1467-9566. 2008.01152.x.

42. Chang CL, Hsu MY. The study that applies artificial intelligence and logistic regression for assistance in differential diagnostic of pancreatic cancer. Expert Syst Appl [Internet]. Elsevier Ltd; 2009;36:10663-72. https://doi.org/10.1016/j.eswa.2009.02.046.

43. Charette R. EHRs: Electronic Health Records or Exceptional Hidden Risks? Commun ACM. 2006;49. https://doi.org/10.1145/ 1132469.1132495

44. Platt N, Tarafdar M, Williams RA. The Complementary Roles of Health Information Systems and Relational Coordination in Alcohol Care Pathways: The Case of a U.K. Hospital. TwentySeventh Eur Conf Inf Syst. 2019.

45. Obeng O, Paul S. Understanding HIPAA compliance practice in healthcare organizations in a cultural context. 25th Am Conf Inf Syst. 2019.

46. De Ramón Fernández A, Ruiz Fernández D, Prieto Sánchez MT. A decision support system for predicting the treatment of ectopic pregnancies. Int J Med Inform [Internet]. Elsevier; 2019;129:198-204. https://doi.org/10.1016/j.ijmedinf.2019.06. 002.

47. Spohrer J. Banavar G. Cognition as a Service: An Industry Perspective. AI Mag; 2017. p. 36.
48. Nasirian F, Ahmadian M. Lee O. AI-Based Voice Assistant Systems: Evaluating from the Interaction and Trust Perspectives. Am Conf Inf Syst; 2017. p. 1-10.

49. Dellermann D, Lipusch N, Ebel P, Leimeister J. Design principles for a hybrid intelligence decision support system for business model validation. Electron Mark. 2018;1-19. https://doi. org/10.1007/s12525-018-0309-2.

50. Kersting K. Machine Learning and Artificial Intelligence: Two Fellow Travelers on the Quest for Intelligent Behavior in Machines. Front Big Data [Internet]. 2018;1. https://doi.org/10. 3389/fdata.2018.00006.

51. Bosse S, Maniry D, Müller KR, Wiegand T, Samek W. Deep Neural Networks for No-Reference and Full-Reference Image Quality Assessment. IEEE Trans Image Process. 2018;27:20619. https://doi.org/10.1109/TIP.2017.2760518.

52. Lai S, Seng J, Lin W. Prediction of financial distress with text mining and hidden Markov model. Twenty-Second Pacific Asia Conf Inf Syst. 2018.

53. Panch T, Szolovits P, Atun R. Artificial intelligence, machine learning and health systems. J Glob Health. 2018;8:1-8. https:// doi.org/10.7189/jogh.08.020303.

54. Rajkomar A, Dean J, Kohane I. Machine Learning in Medicine. N Engl J Med [Internet]. 2019;380:1347-58. https://doi.org/10. 1056/NEJMra1814259.

55. Mazzocco T, Hussain A. Novel logistic regression models to aid the diagnosis of dementia. Expert Syst Appl Elsevier Ltd. 2012;39:3356-61. https://doi.org/10.1016/j.eswa.2011.09.023.

56. Lu J, Song E, Ghoneim A, Alrashoud M. Machine learning for assisting cervical cancer diagnosis: An ensemble approach. Futur Gener Comput Syst [Internet]. 2020;106:199-205. https://doi. org/10.1016/j.future.2019.12.033.

57. Solan Z, Horn D, Ruppin E, Edelman S. Unsupervised learning of natural languages. Proc Natl Acad Sci USA. 2005;102:1162934. https://doi.org/10.1073/pnas.0409746102.

58. Karpischek S, Michahelles F, Fleisch E. Detecting incorrect product names in online sources for product master data. Electron Mark. 2014;24:151-60. https://doi.org/10.1007/ s12525-013-0136-4.

59. Deo RC. Machine Learning in Medicine. Circulation [Internet]. 2015;132:1920-30. https://doi.org/10.1161/CIRCULATIONAHA. 115.001593.

60. Alanazi HO, Abdullah AH, Qureshi KN. A Critical Review for Developing Accurate and Dynamic Predictive Models Using Machine Learning Methods in Medicine and Health Care. J Med Syst [Internet]. 2017;41:69. https://doi.org/10.1007/ s10916-017-0715-6.

61. Goodfellow I, Bengio Y, Courville A. Deep Learning. 1st ed. Cambridge, MA: MIT Press; 2016.

62. Fogassi L, Ferrari PF, Gesierich B, Rozzi S, Chersi F, Rizzolotti G. Neuroscience: Parietal lobe: From action organization to intention understanding. Science (80- ). 2005;308:662-7. https:// doi.org/10.1126/science.1106138.

63. LeCun Y, Bengio Y, Hinton G. Deep learning. Nature [Internet]. 2015;521:436-44. https://doi.org/10.1038/nature14539.

64. Jain AK, Jianchang Mao, Mohiuddin KM. Artificial neural networks: a tutorial. Computer (Long Beach Calif) [Internet]. 1996;29:31-44. https://doi.org/10.1109/2.485891.

65. Rudin C. Stop explaining black box machine learning models for high stakes decisions and use interpretable models instead. Nat Mach Intell [Internet]. 2019;1:206-15. https://doi.org/10.1038/ s42256-019-0048-x.

66. Mishra S, Yamasaki T, Imaizumi H. Supervised classification of Dermatological diseases by Deep learning. 2018;1-6.

67. Jin Y, Qin C, Huang Y, Zhao W, Liu C. Multi-domain modeling of atrial fibrillation detection with twin attentional convolutional 
long short-term memory neural networks. Knowledge-Based Syst [Internet]. Elsevier B.V.; 2020;193:105460. https://doi.org/10. 1016/j.knosys.2019.105460.

68. Wong TT. Performance evaluation of classification algorithms by k-fold and leave-one-out cross validation. Pattern Recognit [Internet]. 2015;48:2839-46. https://doi.org/10.1016/j.patcog. 2015.03.009.

69. Bendavid A. Comparison of classification accuracy using Cohen's Weighted Kappa. Expert Syst Appl [Internet]. 2008;34:825-32. https://doi.org/10.1016/j.eswa.2006.10.022.

70. Sokolova M, Lapalme G. A systematic analysis of performance measures for classification tasks. Inf Process Manag [Internet]. 2009;45:427-37. https://doi.org/10.1016/j.ipm.2009.03.002.

71. Webster J, Watson R. Analyzing the past to prepare for the future: Writing a literature review. MIS Q. 2002;26:13-23. https://doi. org/10.2307/4132319.

72. Temple J. Conducting Research Literature Reviews: from the Internet to Paper. J Adv Nurs [Internet]. 2006;55:792-792. https://doi.org/10.1111/j.1365-2648.2006.04033.x.

73. Guzzo RA, Jackson SE, Katzell RA. Meta-analysis analysis Res Organ Behav. 1987;9:407-42.

74. Yang H, Tate M. A descriptive literature review and classification of cloud computing research. Commun Assoc Inf Syst. 2012;31:35-60. https://doi.org/10.17705/1 cais.03102.

75. Boell SK, Blair W. www.litbaskets.io , an IT Artifact Supporting Exploratory Literature Searches. Australas Conf Inf Syst. 2019.

76. Bem DJ. Writing a review article for Psychological Bulletin. Psychol Bull [Internet]. 1995;118:172-7. https://doi.org/10.1037/ 0033-2909.118.2.172.

77. Chae YM, Ho SH. Comparison of Alternative Knowledge Model for the Diagnosis of Asthma. Expert Syst Appl. 1996;II:423-9.

78. Ogah US, Zirra PB, Sarjiyus O. Knowledge Based System Design for Diagnosis of Hepatitis B Virus ( Hbv ) Using Generalized Regression Neural Network ( Grnn ) Knowledge Based System Design for Diagnosis of Hepatitis B Virus ( Hbv ) Using Generalized Regression Neural Network ( Grnn ). Am J Comput Eng. 2017;1:1-19.

79. Lin RH. An intelligent model for liver disease diagnosis. Artif Intell Med. 2009;47:53-62. https://doi.org/10.1016/j.artmed. 2009.05.005.

80. Prashanth R, Dutta Roy S, Mandal PK, Ghosh S. High-Accuracy Detection of Early Parkinson's Disease through Multimodal Features and Machine Learning. Int J Med Inform [Internet]. Elsevier Ireland Ltd; 2016;90:13-21. https://doi.org/10.1016/j.ijmedinf. 2016.03.001.

81. Shah PM, Zeb A, Shafi U, Zaidi SFA, Shah MA. Detection of Parkinson disease in brain mri using convolutional neural network. ICAC 2018 - 2018 24th IEEE Int Conf Autom Comput Improv Product through Autom Comput. Chinese Automation and Computing Society in the UK - CACSUK; 2018;1-6. https:// doi.org/10.23919/IConAC.2018.8749023.

82. Abdoh SF, Abo Rizka M, Maghraby FA. Cervical cancer diagnosis using random forest classifier with SMOTE and feature reduction techniques. IEEE Access IEEE. 2018;6:59475-85. https://doi.org/10.1109/ACCESS.2018.2874063.

83. Awais MM, Awan SK. Gastro-intestinal tract inspired computational model for myocardial infarction diagnosis. Expert Syst Appl Elsevier Ltd. 2011;38:5633-41. https://doi.org/10.1016/j. eswa.2010.10.072.

84. Baxt WG, Skora J. Prospective validation of artificial neural network trained to identify acute myocardial infarction. Lancet. 1996;347:12-5. https://doi.org/10.1016/S0140-6736(96) 91555-X.

85. Çetin O, Temurtaş F, Gülgönül Ş. An application of multilayer neural network on hepatitis disease diagnosis using approximations of sigmoid activation function. Dicle Med J / Dicle Tip
Derg. 2015;42:150-7. https://doi.org/10.5798/diclemedj.0921. 2015.02.0550.

86. Eggers KM, Ellenius J, Dellborg M, Groth T, Oldgren J, Swahn E, et al. Artificial neural network algorithms for early diagnosis of acute myocardial infarction and prediction of infarct size in chest pain patients. Int J Cardiol. 2007;114:366-74. https://doi. org/10.1016/j.ijcard.2005.12.019.

87. Parisi L, RaviChandran N, Manaog ML. Feature-driven machine learning to improve early diagnosis of parKinson's disease. Expert Syst Appl [Internet]. Elsevier Ltd; 2018;110:182-90. https://doi.org/10.1016/j.eswa.2018.06.003.

88. Walczak S, Velanovich V. Improving prognosis and reducing decision regret for pancreatic cancer treatment using artificial neural networks. Decis Support Syst [Internet]. Elsevier B.V; 2018;106:110-8. https://doi.org/10.1016/j.dss.2017.12.007.

89. Lee JH, Hwang YN, Park SY, Jeong JH, Kim SM. Diagnosis of osteoporosis by quantification of trabecular microarchitectures from hip radiographs using artificial neural networks. J Comput Theor Nanosci. 2015;12:1115-20. https://doi.org/10.1166/jctn. 2015.3859 .

90. Zhang Y, Ling C. A strategy to apply machine learning to small datasets in materials science. npj Comput Mater [Internet]. Springer US; 2018;4:25. https://doi.org/10.1038/ s41524-018-0081-z.

91. Raudys SJ, Jain AK. Small sample size effects in statistical pattern recognition: recommendations for practitioners. IEEE Trans Pattern Anal Mach Intell [Internet]. 1991;13:252-64. https://doi. org/10.1109/34.75512.

92. Combrisson E, Jerbi K. Exceeding chance level by chance: The caveat of theoretical chance levels in brain signal classification and statistical assessment of decoding accuracy. J Neurosci Methods [Internet]. Elsevier B.V.; 2015;250:126-36. https:// doi.org/10.1016/j.jneumeth.2015.01.010.

93. Kanal L, Chandrasekaran B. On dimensionality and sample size in statistical pattern classification. Pattern Recognit [Internet]. 1971;3:225-34. https://doi.org/10.1016/0031-3203(71)90013-6.

94. Vabalas A, Gowen E, Poliakoff E, Casson AJ. Machine learning algorithm validation with a limited sample size. HernandezLemus E, editor. PLoS One [Internet]. 2019;14:e0224365. https://doi.org/10.1371/journal.pone.0224365.

95. Sartakhti JS, Zangooei MH, Mozafari K. Hepatitis disease diagnosis using a novel hybrid method based on support vector machine and simulated annealing (SVM-SA). Comput Methods Programs Biomed [Internet]. Elsevier Ireland Ltd; 2012;108:570-9. https://doi.org/10.1016/j.cmpb.2011.08.003.

96. Shrivastava VK, Londhe ND, Sonawane RS, Suri JS. Reliable and accurate psoriasis disease classification in dermatology images using comprehensive feature space in machine learning paradigm. Expert Syst Appl [Internet]. Elsevier Ltd; 2015;42:6184-95. https://doi.org/10.1016/j.eswa.2015.03.014.

97. Yu X, Ye C, Xiang L. Application of artificial neural network in the diagnostic system of osteoporosis. Neurocomputing [Internet]. Elsevier; 2016;214:376-81. https://doi.org/10.1016/j.neucom.2016.06.023.

98. Gil D, Johnsson M. Diagnosing Parkinson by using artificial neural networks and support vector machines. Glob J Comput Sci Technol. 2009;9:63-71.

99. Menai MEB. Random forests for automatic differential diagnosis of erythemato-squamous diseases. Int J Med Eng Inform. 2015;7:124-41. https://doi.org/10.1504/IJMEI.2015.068506.

100. Wingate J, Kollia I, Bidaut L, Kollias S. A Unified Deep Learning Approach for Prediction of Parkinson's Disease. IETResearch Journals [Internet]. 2015;1-10.

101. Iliou T, Anagnostopoulos CN, Anastassopoulos G. Osteoporosis detection using machine learning techniques and feature 
selection. Int J Artif Intell Tools. 2015;23:1-9. https://doi.org/ 10.1142/S0218213014500146.

102. Ahmad W, Ahmad A, Iqbal A, Hamayun M, Hussain A, Rehman $\mathrm{G}$, et al. Intelligent hepatitis diagnosis using adaptive neurofuzzy inference system and information gain method. Soft Comput [Internet]. Springer Berlin Heidelberg; 2019;23:10931-8. https://doi.org/10.1007/s00500-018-3643-6.

103. Hariharan M, Polat K, Sindhu R. A new hybrid intelligent system for accurate detection of Parkinson's disease. Comput Methods Programs Biomed [Internet]. Elsevier Ireland Ltd; 2014;113:904-13. https://doi.org/10.1016/j.cmpb.2014.01.004.

104. Kara S, Dirgenali F. A system to diagnose atherosclerosis via wavelet transforms, principal component analysis and artificial neural networks. Expert Syst Appl. 2007;32:632-40. https://doi. org/10.1016/j.eswa.2006.01.043.

105. Liu L, Deng M. An evolutionary artificial neural network approach for breast cancer diagnosis. 3rd Int Conf Knowl Discov Data Mining, WKDD 2010. 2010;593-6. https://doi.org/10. 1109/WKDD.2010.148.

106. Polat H, Danaei Mehr H, Cetin A. Diagnosis of Chronic Kidney Disease Based on Support Vector Machine by Feature Selection Methods. J Med Syst. Journal of Medical Systems; 2017;41. https://doi.org/10.1007/s10916-017-0703-x.

107. Yang YC, Chen H, Wang D, Luo W, Luo BY, Zhang ZT. Diagnosis of pancreatic carcinoma based on combined measurement of multiple serum tumor markers using artificial neural network analysis. Chin Med J (Engl). 2014;127:1891-6. https://doi.org/ 10.3760/cma.j.issn.0366-6999.20133101.

108. Li H, Wang X, Liu C, Wang Y, Li P, Tang H, et al. Dual-input neural network integrating feature extraction and deep learning for coronary artery disease detection using electrocardiogram and phonocardiogram. IEEE Access IEEE. 2019;7:146457-69. https://doi.org/10.1109/ACCESS.2019.2943197.

109. López-Martínez F, Núñez-Valdez ER, Lorduy Gomez J, GarcíaDíaz V. A neural network approach to predict early neonatal sepsis. Comput Electr Eng. 2019;76:379-88. https://doi.org/10. 1016/j.compeleceng.2019.04.015.

110. Ansari S, Shafi I, Ansari A, Ahmad J, Shah SI, Diagnosis of liver disease induced by hepatitis virus using Artificial Neural Networks. IEEE 14th Int Multitopic Conf [Internet]. IEEE. 2011;2011:8-12. https://doi.org/10.1109/INMIC.2011.6151515.

111. Alizadehsani R, Hosseini MJ, Sani ZA, Ghandeharioun A, Boghrati R. Diagnosis of coronary artery disease using costsensitive algorithms. 12th IEEE Int Conf Data Min Work. 2012. p. 9-16. https://doi.org/10.1109/ICDMW.2012.29

112. Chatzimichail E, Rigas A, Paraskakis E, Chatzimichail A. Diagnosis of Asthma Severity Using Artificial Neural Networks. Mediterr Conf Med Biol Eng Comput [Internet]. 2010. p. 600-3. https://doi.org/10.1007/978-3-642-13039-7_151.

113. Sawarkar SD, Ghatol AA, Pande AP. Neural network aided breast cancer detection and diagnosis using support vector machine. Proc Int Conf Neural Networks [Internet]. 2006;2006:158-63.

114. Putatunda S. A Hybrid Deep Learning Approach for Diagnosis of the Erythemato-Squamous Disease. 2019;1-13.

115. Darabi SA. Case-Based-Reasoning System for Feature Selection and Diagnosing Disease. Case Study : Asthma. 2014;5:43-60.

116. Baxt WG, Shofer FS, Sites FD, Hollander JE. A neural computational aid to the diagnosis of acute myocardial infarction. Ann Emerg Med. 2002;39:366-73. https://doi.org/10.1067/mem. 2002.122705

117. Singh A, Pandey B. Diagnosis of liver disease by using least squares support vector machine approach. Int J Healthc Inf Syst Informatics. 2016;11:62-78. https://doi.org/10.4018/IJHISI. 2016040104

118. Devi D, Biswas SK, Purkayastha B. Learning in presence of class imbalance and class overlapping by using one-class SVM and undersampling technique [Internet]. Conn Sci. 2019. https://doi. org/10.1080/09540091.2018.1560394.

119. Burton RJ, Albur M, Eberl M, Cuff SM. Using artificial intelligence to reduce diagnostic workload without compromising detection of urinary tract infections. BMC Med Inform Decis Mak. BMC Medical Informatics and Decision Making; 2019;19:1-11. https://doi.org/10.1186/s12911-019-0878-9.

120. Kara S, Güven A, Okandan M, Dirgenali F. Utilization of artificial neural networks and autoregressive modeling in diagnosing mitral valve stenosis. Comput Biol Med. 2006;36:473-83. https://doi.org/10.1016/j.compbiomed.2005.01.007.

121. Tenório JM, Hummel AD, Cohrs FM, Sdepanian VL, Pisa IT, De Fátima MH. Artificial intelligence techniques applied to the development of a decision-support system for diagnosing celiac disease. Int J Med Inform. 2011;80:793-802. https://doi.org/10. 1016/j.ijmedinf.2011.08.001.

122. Bucak IÖ, Baki S. Diagnosis of liver disease by using CMAC neural network approach. Expert Syst Appl. 2010;37:6157-64. https://doi.org/10.1016/j.eswa.2010.02.112.

123. Mani S, Ozdas A, Aliferis C, Varol HA, Chen Q, Carnevale R, et al. Medical decision support using machine learning for early detection of late-onset neonatal sepsis. J Am Med Informatics Assoc. 2014;21:326-36. https://doi.org/10.1136/amiajnl2013-001854.

124. Vasanthselvakumar R, Balasubramanian M, Palanivel S. Detection and Classification of Kidney Disorders using Deep Learning Method. J Mech Contin Math Sci [Internet]. 2019;14:3045-51. https://doi.org/10.26782/jmcms.2019.04.00021

125. Knight W. The Dark Secret at the Heart of AI. MIT Technol Rev. 2017;

126. Abbod MF, Catto JWF, Linkens DA, Wild PJ, Herr A, Wissmann $\mathrm{C}$, et al. Artificial intelligence technique for gene expression profiling of urinary bladder cancer. IEEE Intell Syst. 2006;646-51. https://doi.org/10.1109/IS.2006.348495.

127. Devikanniga D, Joshua Samuel Raj R. Classification of osteoporosis by artificial neural network based on monarch butterfly optimisation algorithm. Healthc Technol Lett. 2018;5:70-5. https:// doi.org/10.1049/htl.2017.0059.

128. Cho P-C, Chen W-H. A Double Layer Dementia Diagnosis System Using Machine Learning Techniques. Commun Comput Inf Sci [Internet]. 2012. p. 402-12. https://doi.org/10.1007/978-3642-32909-8_41.

129. Kara S, Güven A, Öner AÖ. Utilization of artificial neural networks in the diagnosis of optic nerve diseases. Comput Biol Med. 2006;36:428-37. https://doi.org/10.1016/j.compbiomed.2005.01. 003.

130. Pardee AB, Stein GS. The Biology and Treatment of Cancer: Understanding Cancer. Biol Treat Cancer Underst Cancer. 2008. https://doi.org/10.1002/9780470374252.

131. Han Y, Yuzgec E, Khasawneh MT. An artificial intelligence approach for breast cancer early risk assessment. IIE Annu Conf Expo. 2013;2013:1712-9.

132. Sun G, Li S, Cao Y, Lang F. Cervical cancer diagnosis based on random forest. Int J Performability Eng. 2017;13:446-57. https:// doi.org/10.23940/ijpe.17.04.p12.446457.

133. Kim S, Jung S, Park Y, Lee J, Park J, Effective liver cancer diagnosis method based on machine learning algorithm. Proc -, . 7th Int Conf Biomed Eng Informatics. BMEI. 2014;2014(2014):7148. https://doi.org/10.1109/BMEI.2014.7002866.

134. Mendis S, Puska P, Norrving B. Global Atlas on Cardiovascular Disease Prevention And Control. Policies: Strategies and Interventions. Geneva; 2011.

135. WHO. The top 10 causes of death [Internet]. 2020 [cited 2020 May 1].

136. Davari Dolatabadi A, Khadem SEZ, Asl BM. Automated diagnosis of coronary artery disease (CAD) patients using optimized 
SVM. Comput Methods Programs Biomed [Internet]. Elsevier Ireland Ltd; 2017;138:117-26. https://doi.org/10.1016/j.cmpb. 2016.10.011.

137. Chiang NYZ, Verbov J. Dermatology - A handbook for medical students \& junior doctors. 1st ed. British Association of Dermatologists; 2014.

138. Xie J, Wang C. Using support vector machines with a novel hybrid feature selection method for diagnosis of erythematosquamous diseases. Expert Syst Appl [Internet]. Elsevier Ltd; 2011;38:5809-15. https://doi.org/10.1016/j.eswa.2010.10.050.

139. Monteiro MP, Batterham RL. The Importance of the Gastrointestinal Tract in Controlling Food Intake and Regulating Energy Balance. Gastroenterology [Internet]. Elsevier Inc.; 2017;152:1707-1717.e2. https://doi.org/10.1053/j.gastro.2017. 01.053 .

140. Drossman DA. Functional gastrointestinal disorders: History, pathophysiology, clinical features, and Rome IV. Gastroenterology [Internet]. Elsevier, Inc; 2016;150:1262-1279.e2. https:// doi.org/10.1053/j.gastro.2016.02.032.

141. Ceylan R, Ceylan M, Özbay Y, Kara S. Fuzzy clustering complex-valued neural network to diagnose cirrhosis disease. Expert Syst Appl [Internet]. Elsevier Ltd; 2011;38:9744-51. https://doi. org/10.1016/j.eswa.2011.02.025.

142. Kumar S, Damodar G, Ravikanth S, Vijayakumar G. An Overview of Infectious Disease. Indian J Pharm Sci Res. 2012;2:63-79.

143. Soundararajan K, Sureshkumar S, Anusuya C. Diagnostics Decision Support System for Tuberculosis using Fuzzy Logic. IRACST - Int J Comput Sci Inf Technol Secur. 2012;2:684-9.

144. Hoffmann GF, Zschocke J, Nyhan WL. Inherited Metabolic Diseases: A Clinical Approach. Springer, editor. Berlin; 2010.

145. Chan KY, Ling SH, Dillon TS, Nguyen HT. Diagnosis of hypoglycemic episodes using a neural network based rule discovery system. Expert Syst Appl. 2011;38:9799-808. https://doi.org/10. 1016/j.eswa.2011.02.020.

146. Gharehchopogh FS, Molany M, Mokri FD. Using Artificial Neucal Network in Diagnosis of Thyroid Disease: A Case Study. Int J Inf Sci Tech. 2013;3:49-61. https://doi.org/10.5121/ijcsa.2013. 3405.

147. Price BH, Adams RD, Coyle JT. Neurology and psychiatry: Closing the great divide. Neurology. 2000;54:8-14. https://doi.org/ 10.1212/WNL.54.1.8.

148. Senturk ZK. Early diagnosis of Parkinson's disease using machine learning algorithms. Med Hypotheses [Internet]. Elsevier Ltd; 2020;138:109603. https://doi.org/10.1016/j.mehy.2020. 109603.

149. Erkan U, Thanh DNH. Autism Spectrum Disorder Detection with Machine Learning Methods. Curr Psychiatry Res Rev. 2019;15:297308. https://doi.org/10.2174/2666082215666191111121115.

150. O'Hara K. Paediatric pharmacokinetics and drug doses. Aust Prescr [Internet]. 2016;39:208-10. https://doi.org/10.18773/ austprescr.2016.071.

151. Mantzaris D, Anastassopoulos G, Adamopoulos A, Gardikis S. A non-symbolic implementation of abdominal pain estimation in childhood. Inf Sci (Ny). 2008;178:3860-6. https://doi.org/10. 1016/j.ins.2008.06.015.

152. Vogelmeier CF, Criner GJ, Martinez FJ, Anzueto A, Barnes PJ, Bourbeau J, et al. Global Strategy for the Diagnosis, Management and Prevention of Chronic Obstructive Lung Disease 2017 Report: GOLD Executive Summary. Respirology. 2017;22:575601. https://doi.org/10.1111/resp.13012.

153. Decramer M, Janssens W, Miravitlles M. Chronic obstructive pulmonary disease. Lancet [Internet]. Elsevier Ltd; 2012;379:134151. https://doi.org/10.1016/S0140-6736(11)60968-9.

154. Burton-Jones A, Akhlaghpour S, Ayre S, Barde P, Staib A, Sullivan C. Changing the conversation on evaluating digital transformation in healthcare: Insights from an institutional analysis. Inf Organ. 2020;30. https://doi.org/10.1016/j.infoandorg. 2019.100255.

155. Kotsiantis SB. Supervised machine learning: A review of classification techniques. Inform. 2007;31:249-68. https://doi.org/ 10.31449/inf.v31i3.148.

156. Shalev-Shwartz S, Ben-David S. Understanding Machine Learning: From Theory to Algorithms. 1st ed. Cambridge University Press; 2014.

157. Altman NS. An introduction to kernel and nearest-neighbor nonparametric regression. Am Stat. 1992;46:175-85. https://doi.org/ 10.1080/00031305.1992.10475879.

158. Breimann L. Random Forests. Mach Learn. 2001;45:5-32. https://doi.org/10.1023/A:1010933404324.

159. Liu W, Wang Z, Liu X, Zeng N, Liu Y, Alsaadi FE. A survey of deep neural network architectures and their applications. Neurocomputing [Internet]. 2017;234:11-26. https://doi.org/10.1016/j. neucom.2016.12.038.

160. Adeli M, Bigdeli N, Afshar K. New hybrid hepatitis diagnosis system based on Genetic algorithm and adaptive network fuzzy inference system. 2013 21st Iran Conf Electr Eng ICEE 2013. 2013; https://doi.org/10.1109/IranianCEE.2013.6599872.

161. Adem K, Kiliçarslan S, Cömert O. Classification and diagnosis of cervical cancer with softmax classification with stacked autoencoder. Expert Syst Appl. 2019;115:557-64. https://doi.org/10. 1016/j.eswa.2018.08.050.

162. Alile S. An Ischemic Heart Disease Prediction Model Based on Observed Symptoms Using Machine Learning. 2020;8-23. https://doi.org/10.22362/ijcert/2020/v7/i09/v7i0902.

163. Arabasadi Z, Alizadehsani R, Roshanzamir M, Moosaei H, Yarifard AA. Computer aided decision making for heart disease detection using hybrid neural network-Genetic algorithm. Comput Methods Programs Biomed [Internet]. Elsevier Ireland Ltd; 2017;141:19-26. https://doi.org/10.1016/j.cmpb.2017.01.004.

164. Babaoğlu I, Findik O, Bayrak M. Effects of principle component analysis on assessment of coronary artery diseases using support vector machine. Expert Syst Appl. 2010;37:2182-5. https://doi. org/10.1016/j.eswa.2009.07.055.

165. Baxt WG. Use of an Artificial Neural Network for Data Analysis in Clinical Decision-Making: The Diagnosis of Acute Coronary Occlusion. Neural Comput. 1990;2:480-9. https://doi.org/10. 1162/neco.1990.2.4.480.

166. Baxt WG. Use of an artificial neural network for the diagnosis of myocardial infarction. Ann Intern Med. 1991;115:843-8. https:// doi.org/10.7326/0003-4819-115-11-843.

167. Baxt WG. Analysis of the clinical variables driving decision in an artificial neural network trained to identify the presence of myocardial infarction. Ann Emerg Med. 1992;21:1439-44. https:// doi.org/10.1016/S0196-0644(05)80056-3.

168. Baxt WG. A neural network trained to identify the presence of myocardial infarction bases diagnostic decision on nonlinear relationships between input variables. Neural Comput Appl [Internet]. 1993;1:176-82. https://doi.org/10.1007/BF01414944.

169. Baxt WG, Shofer FS, Sites FD, Hollander JE. A neural network aid for the early diagnosis of cardiac ischemia in patients presenting to the emergency department with chest pain. Ann Emerg Med. 2002;40:575-83. https://doi.org/10.1067/mem.2002. 129171.

170. Berikol GB, Yildiz O, Özcan T. Diagnosis of Acute Coronary Syndrome with a Support Vector Machine. J Med Syst. 2016;40:1-8. https://doi.org/10.1007/s10916-016-0432-6.

171. Chazaro A, Cravens G, Eberhart R. Myocardial infarction diagnosis by a neural network. Proc 20th Annu Znternational Conf ZEEE Eng Med Biol Soc. 1998. p. 1121-4. https://doi.org/10. 1109/iembs.1998.747068. 
172. Chen Y, Li M, Hao F, Han W, Niu D, Wang C, Classification of glomerular spikes using Convolutional Neural Network. Proc, . Conf Artif Intell Healthc [Internet]. New York, NY, USA: ACM. 2020;2020:254-8. https://doi.org/10.1145/3433996.3434043.

173. Ding S, Hu S, Pan J, Li X, Li G, Liu X. A homogeneous ensemble method for predicting gastric cancer based on gastroscopy reports. Expert Syst [Internet]. 2020;37:1-14. https://doi.org/10. 1111/exsy.12499.

174. Dutta A, Batabyal T, Basu M, Acton ST. An efficient convolutional neural network for coronary heart disease prediction. Expert Syst Appl [Internet]. Elsevier Ltd; 2020;159:113408. https://doi.org/10.1016/j.eswa.2020.113408.

175. Hamedan F, Orooji A, Sanadgol H, Sheikhtaheri A. Clinical decision support system to predict chronic kidney disease: A fuzzy expert system approach. Int J Med Inform [Internet]. Elsevier; 2020;138:104134. https://doi.org/10.1016/j.ijmedinf.2020. 104134.

176. Harrison RF, Kennedy RL. Artificial neural network models for prediction of acute coronary syndromes using clinical data from the time of presentation. Ann Emerg Med. 2005;46:431-9. https://doi.org/10.1016/j.annemergmed.2004.09.012.

177. Hirschauer TJ, Adeli H, Buford JA. Computer-Aided Diagnosis of Parkinson's Disease Using Enhanced Probabilistic Neural Network. J Med Syst. 2015;39. https://doi.org/10.1007/ s10916-015-0353-9.

178. Husain NP, Arisa NN, Rahayu PN, Arifin AZ, Herumurti D. Least Squares Support Vector Machines Parameter Optimization Based. 2017;1:43-9.

179. Içer $S$, Kara $S$, Güven A. Comparison of multilayer perceptron training algorithms for portal venous doppler signals in the cirrhosis disease. Expert Syst Appl. 2006;31:406-13. https://doi. org/10.1016/j.eswa.2005.09.037.

180. Karabayir I, Goldman SM, Pappu S, Akbilgic O. Gradient boosting for Parkinson's disease diagnosis from voice recordings. BMC Med Inform Decis Mak [Internet]. BMC Medical Informatics and Decision Making; 2020;20:228. https://doi.org/ 10.1186/s12911-020-01250-7.

181. Kara S, Dirgenali F. A SYSTEM TO DIAGNOSE THE ATHEROSCLEROSIS USING WAVELET TRANSFORMATION, PRINCIPAL COMPONENT ANALYSIS AND ARTIFICIAL NEURAL NETWORK Sad 1 k Kara , Fatma Dirgenali. 3rd Eur Med Biol Eng Conf. 2005.

182. Kavitha MS, Asano A, Taguchi A, Kurita T, Sanada M. Diagnosis of osteoporosis from dental panoramic radiographs using the support vector machine method in a computer-aided system. BMC Med Imaging. 2012;12:1-11. https://doi.org/10.1186/ 1471-2342-12-1.

183. Kele A, Kele A, Yavuz U. Expert system based on neurofuzzy rules for diagnosis breast cancer. Expert Syst Appl. 2011;38:5719-26. https://doi.org/10.1016/j.eswa.2010.10.061.

184. Kennedy RL, Harrison RF, Burton AM, Fraser HS, Hamer WG, MacArthur D, et al. An artificial neural network system for diagnosis of acute myocardial infarction (AMI) in the accident and emergency department: Evaluation and comparison with serum myoglobin measurements. Comput Methods Programs Biomed. 1997;52:93-103. https://doi.org/10.1016/S0169-2607(96)01782-8.

185. Kojuri J, Boostani R, Dehghani P, Nowroozipour F, Saki N. Prediction of acute myocardial infarction with artificial neural networks in patients with nondiagnostic electrocardiogram. $\mathbf{J}$ Cardiovasc Dis Res. 2015;6:51-9. https://doi.org/10.5530/jcdr. 2015.2.2.

186. Lahsasna A, Ainon RN, Zainuddin R, Bulgiba A. Design of a fuzzy-based decision support system for coronary heart disease diagnosis. J Med Syst. 2012;36:3293-306. https://doi.org/10. 1007/s10916-012-9821-7.
187. Laurentinus K, Sulaiman R, Panca Juniawan F, Yuny Sylfania D, Kurniawan P, Disease DFESACFIEDOS, et al. 8th Int Conf Cyber IT Serv Manag [Internet]. IEEE. 2020;2020:1-7. https:// doi.org/10.1109/CITSM50537.2020.9268830.

188. Maclin PS, Dempsey J. Using an artificial neural network to diagnose hepatic masses. J Med Syst. 1992;16:215-25. https://doi. org/10.1007/BF01000274.

189. Maclin PS, Dempsey J, Brooks J, Rand J. Using neural networks to diagnose cancer. J Med Syst. 1991;15:11-9. https://doi.org/10. 1007/BF00993877.

190. Mandal I, Sairam N. New machine-learning algorithms for prediction of Parkinson's disease. Int J Syst Sci [Internet]. 2012;45:647-66. https://doi.org/10.1080/00207721.2012. 724114 .

191. Mantzaris D, Vrizas M, Trougkakos S, Priska E, Vadikolias K. Artificial Neural Networks for Estimation of Dementias Types. Artif Intell Appl. 2014;2014:74-82. https://doi.org/10.15764/aia. 2014.01006.

192. Medjahed SA. Urinary System Diseases Diagnosis Using Machine Learning Techniques. Int J Intell Syst Appl. 2015;7:1-7. https://doi.org/10.5815/ijisa.2015.05.01.

193. Neshat M. Diagnosing Hepatitis Disease by Using Fuzzy Hopfield Neural Network. Annu Res Rev Biol. 2014;4:2709-21. https://doi.org/10.9734/arrb/2014/9183.

194. Neshat M, Masoumi A, Rajabi M, Jafari H. Using Fuzzy Hopfield Neural Network for Diagnosis of the Hepatitis Disease. Turkish J Eng Sci Technol. 2014;02:63-75.

195. Ng EYK, Acharya UR, Keith LG, Lockwood S. Detection and differentiation of breast cancer using neural classifiers with first warning thermal sensors. Inf Sci (Ny). 2007;177:4526-38. https://doi.org/10.1016/j.ins.2007.03.027.

196. Ng EYK, Kee EC. INTEGRATIVE COMPUTER-AIDED DIAGNOSTIC WITH BREAST THERMOGRAM. J Mech Med Biol [Internet]. 2007;07:1-10. https://doi.org/10.1142/ S0219519407002091.

197. Ouyang N, Ikeda M, Yamauchi K. Using a neural network to diagnose anterior wall myocardial infarction. IEEE Int Conf Neural Networks - Conf Proc. 1997;1:59-61. https://doi.org/10.1109/ ICNN.1997.611636.

198. Özbay Y. A new method for diagnosis of cirrhosis disease: Complex-valued artificial neural network. J Med Syst. 2008;32:36977. https://doi.org/10.1007/s10916-008-9142-z.

199. Ozyilmaz L, Yildirim T. Artificial Neural Networks for Diagnosis of Hepatitis Disease. Proc Int Jt Conf Neural Networks. 2003;1:586-9. https://doi.org/10.1109/ijcnn.2003.1223422.

200. Pahuja G, Nagabhushan TN, Prasad B, Pushkarna R. Early detection of Parkinson's disease through multimodal features using machine learning approaches. Int J Signal Imaging Syst Eng. 2018;11:31-43. https://doi.org/10.1504/IJSISE.2018.090605.

201. Prashanth R, Dutta Roy S. Early detection of Parkinson's disease through patient questionnaire and predictive modelling. Int J Med Inform [Internet]. Elsevier Ireland Ltd; 2018;119:75-87. https:// doi.org/10.1016/j.ijmedinf.2018.09.008.

202. Rajamani L, Rajamani A. Application of neural network to detection of cardiac disease. Proc 2011 Int Conf Artif Intell ICAI 2011. 2011;2:750-5.

203. Rouhani M, Haghighi MM. The diagnosis of hepatitis diseases by support vector machines and artificial neural networks. 2009 Int Assoc Comput Sci Inf Technol - Spring Conf IACSIT-SC 2009. 2009;456-8. https://doi.org/10.1109/IACSIT-SC.2009.25.

204. Rufai A, S., U.Idriss US, Umar M. Using Artificial Neural Networks to Diagnose Heart Disease. Int J Comput Appl. 2018;182:1-6. https://doi.org/10.5120/ijca2018917938.

205. Sali R, Shavandi H, Sadeghi M. A clinical decision support system based on support vector machine and binary particle swarm 
optimisation for cardiovascular disease diagnosis. Int J Data Min Bioinform. 2016;15:312-27. https://doi.org/10.1504/IJDMB. 2016.078150.

206. Samadiani N, Hassani Z. A System for Diagnosis of Coronary Artery Disease based on Neural Networks and Machine Learning Algorithms. Int J Comput Appl. 2018;181:36-41. https://doi.org/ 10.5120/ijca2018917784.

207. Ghumbre SU, Ghatol AA. Heart disease diagnosis using machine learning Algorithm. Adv Intell Soft Comput. 2012;132 AISC:217-25. https://doi.org/10.1007/978-3-642-27443-5-25.

208. Singh A, Pandey B. An efficient diagnosis system for detection of liver disease using a novel integrated method based on Principal Component Analysis and K-Nearest Neighbor (PCA-KNN). Int J Healthc Inf Syst Informatics. 2016;11:56-69. https://doi.org/ 10.4018/IJHISI.2016100103.

209. Singh A, Pandey B. Diagnosis of Liver Disease Using Correlation Distance Metric Based K-Nearest Neighbor Approach. Intell Syst Technol Appl [Internet]. 2016. p. 845-56. https://doi.org/ 10.1007/978-3-319-47952-1_67.

210. Singh A, Pandey B. Liver disorder diagnosis using linear, nonlinear and decision tree classification algorithms. Int J Eng Technol. 2016;8:2059-69. https://doi.org/10.21817/ijet/2016/v8i5/160805424.

211. M Sohani B Makki N Sadati KK Kermani A Riazati. A neurofuzzy approach to diagnosis of neonatal jaundice. 2006 1st Bio-Inspired Model Network Inf Comput Syst BIONETICS 2006https://doi.org/10.1109/BIMNICS.2006.361808.

212. Sontakke S, Lohokare J, Dani R, Diagnosis of liver diseases using machine learning. . Int Conf Emerg Trends Innov ICT. ICEI. 2017;2017(2017):129-33. https://doi.org/10.1109/ETIICT. 2017.7977023 .

213. Steinbuss G, Kriegsmann K, Kriegsmann M. Identification of Gastritis Subtypes by Convolutional Neuronal Networks on Histological Images of Antrum and Corpus Biopsies. Int J Mol Sci [Internet]. 2020;21:6652. https://doi.org/10.3390/ijms21186652.

214. Tang J, Yang B, Adams MP, Shenkov NN, Klyuzhin IS, Fotouhi $\mathrm{S}$, et al. Artificial Neural Network-Based Prediction of Outcome in Parkinson's Disease Patients Using DaTscan SPECT Imaging
Features. Mol Imaging Biol. 2019;21:1165-73. https://doi.org/ 10.1007/s11307-019-01334-5.

215. Tiwari AK. Machine Learning Based Approaches for Prediction of Parkinson's Disease. Mach Learn Appl An Int J. 2016;3:33-9. https://doi.org/10.5121/mlaij.2016.3203.

216. Uchino E, Suzuki K, Sato N, Kojima R, Tamada Y, Hiragi S, et al. Classification of glomerular pathological findings using deep learning and nephrologist-AI collective intelligence approach. Int J Med Inform [Internet]. Elsevier; 2020;141:104231. https:// doi.org/10.1016/j.ijmedinf.2020.104231.

217. Varuna S, Revathi K, Nagamani T. Prediction of Coronary Artery Disease Using Genetic Algorithm Based Feature Selection and Random Forest Classifier. Int J Adv Res Sci Eng. 2017;6:293-301.

218. Wu W, Zhou H. Data-driven diagnosis of cervical cancer with support vector machine-based approaches. IEEE Access. 2017;5:25189-95. https://doi.org/10.1109/ACCESS.2017.2763984.

219. Xu Y, Li D, Chen Q, Fan Y. Full supervised learning for osteoporosis diagnosis using micro-CT images. Microsc Res Tech. 2013;76:333-41. https://doi.org/10.1002/jemt.22171.

220. Yang TF, Devine B, Macfarlane PW. Artificial neural networks for the diagnosis of atrial fibrillation. Med Biol Eng Comput. 1994;32:615-9. https://doi.org/10.1007/BF02524235.

221. Yogitha R, Manjunatha PC. Diagnosis of liver diseases using machine learning. Int J Res Eng. 2017;2:129-33. https://doi.org/ 10.1109/ETIICT.2017.7977023.

222. Yuan KC, Tsai LW, Lee KH, Cheng YW, Hsu SC, Lo YS, et al. The development an artificial intelligence algorithm for early sepsis diagnosis in the intensive care unit. Int J Med Inform [Internet]. Elsevier; 2020;141:104176. https://doi.org/10.1016/j. ijmedinf.2020.104176.

223. Brendel AB, Mirbabaie M, Lembcke TB, Hofeditz L. Ethical Management of Artificial Intelligence. Sustainability, MDPI, Open Access Journal, vol. 13(4), pages 1-18, February 2021.

Publisher's Note Springer Nature remains neutral with regard to jurisdictional claims in published maps and institutional affiliations. 